\title{
Personality, performance, and the effects of stress on checkered pufferfish (Sphoeroides testudineus)
}

\author{
by
}

Naomi Pleizier

A thesis submitted to the Faculty of Graduate and Postdoctoral Affairs in partial fulfillment of the requirements for the degree of

Master of Science

in

\section{Biology}

Carleton University

Ottawa, Ontario

(C) 2015, Naomi Pleizier 


\begin{abstract}
Few studies focus on the mechanisms that regulate consistent individual-level differences in behaviour (i.e., personality) in wild animals, despite their potential evolutionary and ecological implications. I examined whether wild checkered pufferfish (Sphoeroides testudineus) have consistent individual-level differences in locomotor activity, threatresponse behaviour, swimming ability, and puffing performance. I also evaluated the relationships between these personality and performance traits. Personality and performance were compared to movements in the field. In addition, I tested whether a treatment of the stress hormone cortisol would alter personality and performance. Pufferfish exhibited personalities but these were not associated with performance or recapture in the field. Performance was consistent between the lab and the natural enclosure but activity was not. The cortisol treatment did not modify personality or performance, which suggests that these traits do not represent a stress-coping syndrome. I conclude by recommending future directions for research on stress and personality in wild animals.
\end{abstract}




\section{Acknowledgements}

I would like to thank Steven J. Cooke, my supervisor, for his continuous support and enthusiasm throughout my master's program. I also owe thanks to my co-authors, Alexander D. M. Wilson and Aaron D. Shultz, for their contributions and feedback, as well as their mentorship throughout the preparation of this thesis. I appreciate the insights and time offered by my committee members, Pat Walsh and Kathleen Gilmour, and my internal examiner, Jayne Yack. I would like to acknowledge Felicia Cull for her advice. I would like to recognize Zach Zuckerman, Liane Nowell, Kelly Hannan, Jenn Magel, Ian Bouyoucos, Catherine Smadja, and many others at the Cape Eleuthera Institute for their eagerness to chase pufferfish around in the field and for their help in the lab. Lee Gutowsky and Jake Brownscombe offered valuable statistical advice. I also give my heartfelt thanks to my family and friends for their encouragement throughout this project. Funding for this research was provided by the Canada Research Chairs Program and a Natural Sciences and Engineering Research Council of Canada Discovery Grant to Cooke. 


\section{Table of Contents}

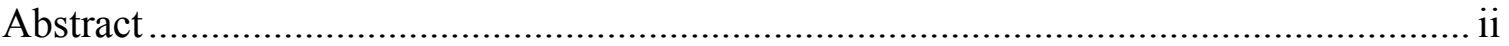

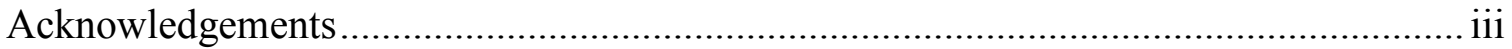

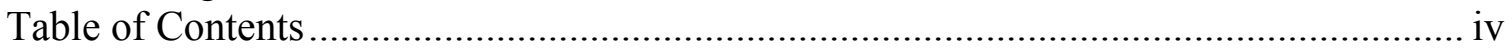

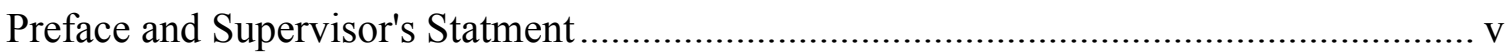

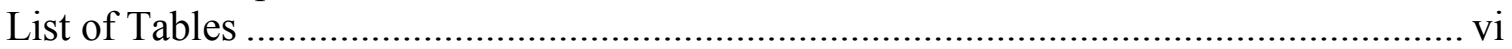

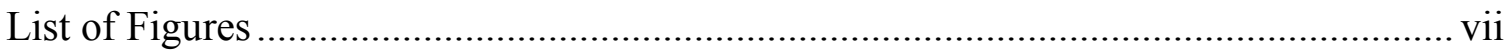

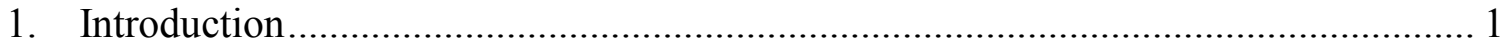

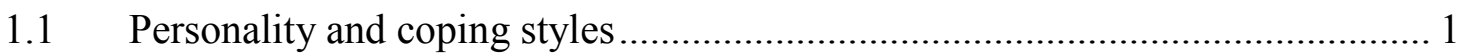

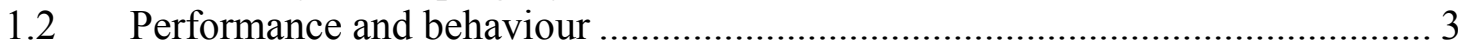

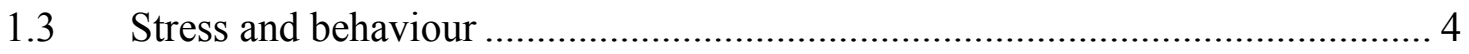

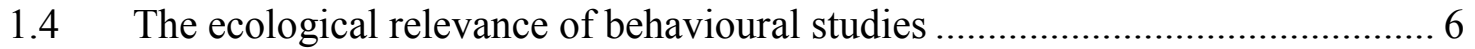

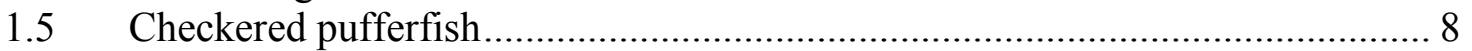

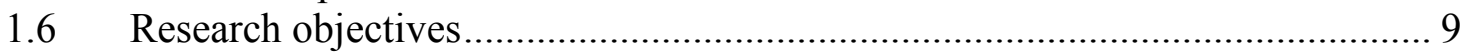

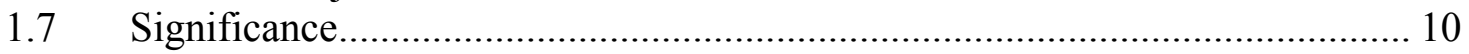

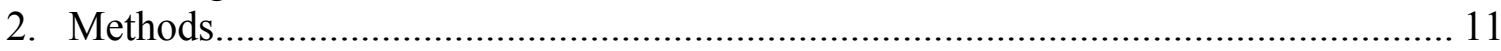

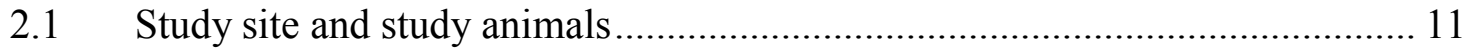

2.2 Repeatability of behaviour and performance in the laboratory ........................ 13

2.3 Cortisol treatment.................................................................................. 15

2.4 Validation in a natural enclosure ................................................................ 17

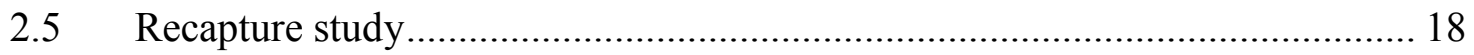

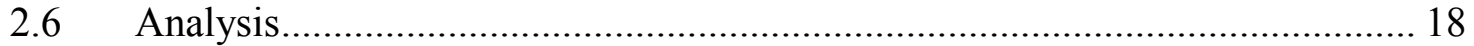

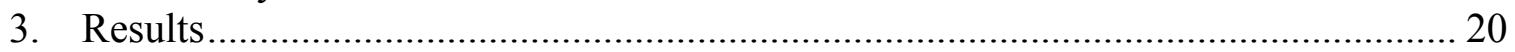

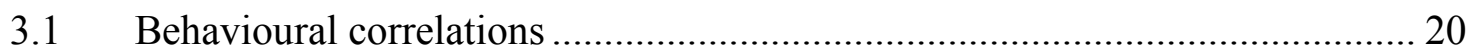

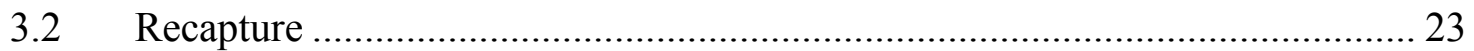

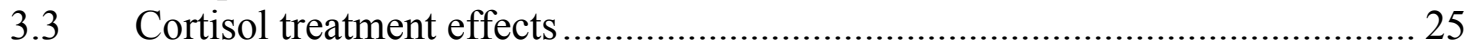

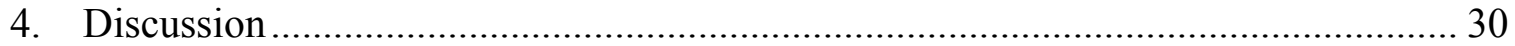

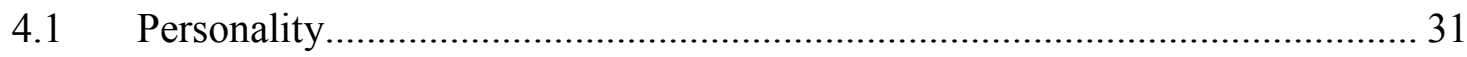

4.2 Behavioural syndromes and stress-coping styles..................................... 32

4.3 Relationships between behaviour, performance, and intrinsic characteristics . 33

4.4 Relationships between behaviour, performance, and external conditions........ 34

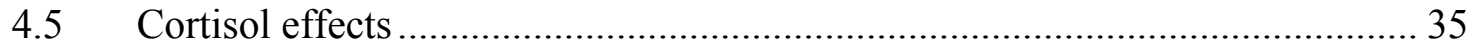

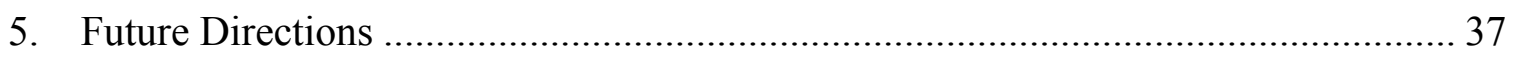

5.1 Methodological considerations for studies on glucocorticoids......................... 38

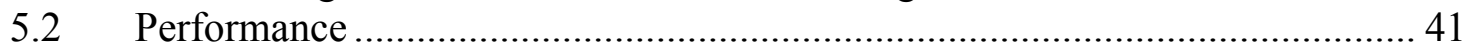

5.3 The effects of context on behaviour and stress physiology ............................ 42

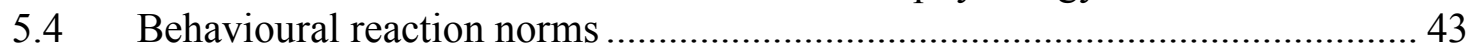

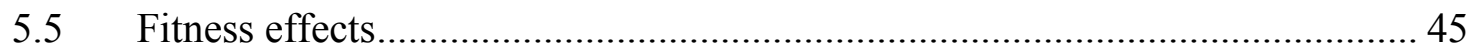

5.6 From individual differences to conservation strategies ................................... 46

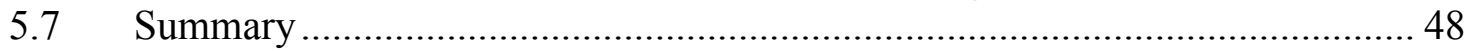

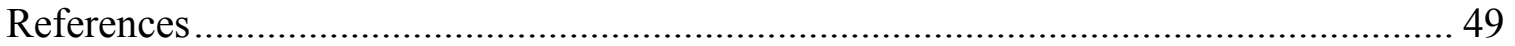

Appendix - Statements of permission from co-authors .................................................... 60 


\section{Preface}

The presented work is a manuscript-based thesis, and chapters $2,3,4$, and portions of chapter 1 have been prepared for submission to a peer-reviewed journal. All presented material is a product of my own work but chapter 2, 3, 4 and portions of chapter 1 were a collaborative effort. I led the research planning, data collection, data analysis, and the writing of the material presented in the co-authored sections integrated in this thesis. Coauthor permission to include these manuscripts in my thesis can be found in the appendix. Wilson and Cooke participated in the planning of the research, Wilson and Shultz assisted with the fieldwork and laboratory components of the study, and all authors offered feedback on chapters 2,3,4, and portions of chapter 1 of the manuscript. Figure 3 has been modified and reprinted with the permission of Felicia Cull.

\section{Supervisor's Statement}

I verify that this thesis is the student's original work. Chapters 2, 3, 4, and sections of chapter 1 are from a manuscript for submission to a peer-reviewed journal and were written in collaboration with co-authors; however, Naomi was the primary actor in all stages of this project, including the writing of this document. She has my permission to include this manuscript as part of her thesis.

Steven J. Cooke 


\section{List of Tables}

Table 1. Correlations between repeated measures of behaviour of checkered pufferfish in the laboratory (January) between an initial trial (initial), a trial at peak cortisol levels (peak cortisol), and a trial after the cortisol treatment had been exhausted (post cortisol).

Table 2. Correlations between repeated measures of behaviour of checkered pufferfish in the laboratory and in a natural enclosure (July).

Table 3. Medians and ranges of the mean values of behaviours measured within individual checkered pufferfish (January).

Table 4. Summary of the terms included in the full model used to predict recapture of checkered pufferfish based on behaviour total length, body condition (Fulton's K), puff duration, locomotor activity, and swimming performance (time to exhaustion) in the laboratory.

Table 5. Summary of the terms included in the full model used to predict recapture of checkered pufferfish based on total length, body condition (Fulton's K), puff duration, locomotor activity, and swimming performance (time to exhaustion) in a natural enclosure. 


\section{List of Figures}

Figure 1. The mangrove swamp surrounding Page Creek in Eleuthera, The Bahamas, at mid-tide

Figure 2. Administering an intramuscular injection of cortisol in a cocoa-butter vehicle to a checkered pufferfish.

Figure 3. Map of the research sites on Cape Eleuthera, Eleuthera, The Bahamas. Page Creek was the fish collection location. A star indicates the Cape Eleuthera Institute (CEI) and a black circle marks the release site for the displacement experiment. The inset shows Eleuthera with the study region highlighted. This figure is reprinted with the permission of Felicia Cull.

Figure 4. The behaviour and performance of individual checkered pufferfish in laboratory arenas and natural enclosures categorized by capture success in their original tidal creek. Fish were recaptured 2, 3, 19, 20, and 23 days after being displaced $\sim 625 \mathrm{~m}$ up-current along the coast. The black line represents the local regression and the $95 \%$ confidence interval is shaded in grey. Data points have been spaced vertically to reduce overlap.

Figure 5. Survival curves of the puff duration of checkered pufferfish. This test was repeated before treatment (Initial), when the cortisol treated group was experiencing peak circulating cortisol (Cortisol) at 48 hours, and after the cortisol treatment had been exhausted (Post) at 4 days. Shaded areas represent the 95\% confidence interval. 23

Figure 6. The number of $10 \mathrm{~cm}$ squares crossed by checkered pufferfish from control and cortisol treated groups during the initial trial (Initial), when cortisol was elevated in the treatment group (Cortisol) at 48 hours, and when cortisol levels had returned to baseline (Post) at 4 days.

Figure 7. Survival curves of the proportion of checkered pufferfish displaying startled behaviour after a weight was dropped and removed from their individual tanks. This test was repeated before treatment (Initial), when the cortisol treated group was experiencing peak circulating cortisol (Cortisol) at 48 hours, and after the cortisol had returned to baseline (Post) at 4 days. The data was censored after 60 seconds. Shaded areas represent

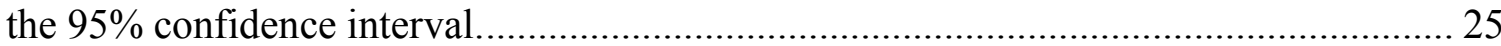

Figure 8. Survival curves of duration of a chase to exhaustion. This test was repeated before treatment (Initial), when the cortisol treated group was experiencing peak circulating cortisol (Cortisol) at 48 hours, and after the cortisol had returned to baseline (Post) at 4 days. Shaded areas represent the $95 \%$ confidence interval. 


\section{Introduction}

\subsection{Personality and coping styles}

There is growing recognition that consistent individual-level differences in behaviour are widespread in natural populations of animals and that they are implicated in evolutionary and ecological processes. Consistent individual-level differences in behaviour have been described in the contexts of animal personality (Gosling, 2001), temperament (Réale et al., 2007), behavioural syndromes (Sih et al., 2004), and stress-coping styles (Koolhaas et al., 1999), and have been documented in a wide variety of invertebrates (Mather and Logue, 2013) and vertebrates (Bell et al., 2009), including fishes (Conrad et al., 2011). We define animal personality broadly as individual-level differences in behaviour that are consistent over time and between contexts (Gosling, 2001; Réale et al., 2007; Sih et al., 2004), whereas we define correlations between different personality traits (e.g., correlations between aggressive behaviour towards conspecifics and responses to predator threats) as behavioural syndromes (Sih et al., 2004). A key evolutionary consequence of consistent individual-level behaviours is that they can at times represent limited plasticity, so that an animal might not be able to express the most suitable behaviour in all contexts (Bell, 2007), which could incur significant fitness consequences for individuals (Smith and Blumstein, 2008; Biro and Stamps, 2008). The fitness consequences of such individual-level variation in behaviour also have the potential to influence higher-order processes such as population growth and persistence, interspecific interactions, community dynamics, and rates of evolution (Dingemanse and Wolf, 2013). Despite the potential costs of behavioural consistency, accumulating evidence suggests that diverse personalities emerge and persist within natural populations (Bell et al., 
2009), possibly as a result of such factors as life-history trade-offs (Biro and Stamps, 2008), fluctuating environmental conditions (Dingemanse et al., 2004), frequency dependent selection (Dall et al., 2004), and sexual selection (Schuett et al., 2011). However, compared to captive-bred mice and rats, relatively few studies focus on the physiological mechanisms that might underpin personality (Duckworth, 2010) and stresscoping styles in wild animals, especially ectotherms (Ø. Øverli et al., 2007; Koolhaas et al., 2010).

Personality traits and physiological stress responses that form coherent sets of traits within groups of individuals are defined as stress-coping styles (Koolhaas et al., 1999). The two extremes of the coping axis are described as proactive and reactive coping. Proactive individuals respond to stressors through aggression and territorial control and tend to be routine forming, whereas reactive individuals respond to stressors with immobility and generally have greater behavioural flexibility (Koolhaas et al., 1999). Different stress-coping styles are also associated with distinct differences in neuroendocrinology, such as a high glucocorticoid response to stressors in reactive individuals and a low glucocorticoid response in proactive individuals (Koolhaas et al., 1999). Rainbow trout (Oncorhynchus mykiss) lines bred for high and low levels of the stress hormone cortisol in response to confinement stress had different behaviour in response to stressors, as well as differences in concentrations of the neurotransmitters serotonin, dopamine, norepinephrine, and their metabolites in various regions of the brain (Øverli et al., 2005). Wild-caught stickelbacks (Gasterosteus aculeatus) also have interindividual differences in behavioural responses to stressors which correspond to individual differences in norepinephrine and serotonin levels in the brain, but not whole- 
body concentrations of immunoreactive corticosteroids (Bell et al., 2007). These stresscoping styles are thought to have evolved as adaptive response patterns to challenges in nature. Proactive individuals tend to be more successful in stable environments, whereas reactive individuals are more successful in unpredictable conditions (Koolhaas et al., 1999). The study of coping styles reveals how suites of physiological and behavioural characteristics can combine to form adaptive stress-coping strategies.

\subsection{Performance and behaviour}

Careau and Garland (2012) suggest that individual differences in performance can elucidate the relationships between physiology, personality, and selection. These authors describe how recent efforts have been made to include behaviour in the pace-of-life syndrome hypothesis (Réale et al., 2010), which posits that combinations of physiological characteristics have evolved with particular life-history traits within species (Ricklefs and Wikelski, 2002; Wikelski et al., 2003). In general, this integration appears to be supported by studies that indicate that there is a positive relationship between activity, aggressiveness, boldness, and metabolic rates (Biro and Stamps, 2010) as well as life-history traits such as fecundity and growth (Biro and Stamps, 2008). The relationship between behaviour and metabolic rates might reflect the association between personality and energetic balance (Biro and Stamps, 2010) or state (Sih and Bell, 2008). However, the link between metabolism and behaviour is not straightforward because an individual can either alter rates of energy acquisition and assimilation to meet the energetic demands of behaviours or reallocated energy from a fixed budget, which would reduce the strength of the relationship between metabolism and behaviour (Careau and Garland, 2012). Also, context appears to have an important effect on the relationship between metabolism and 
behaviour (e.g., Killen et al., 2011; Killen et al., 2012), further complicating the relationship.

Given the difficulty in establishing a direct, causal relationship between metabolism and personality, and given that selection acts more directly on performance than the mechanisms that limit performance, Careau and Garland (2012) advocate that researchers examine the relationships between physiology and performance as well as performance and personality to elucidate the links between physiology, personality, and selection. Despite the promise of this integrative approach and evidence that personality and individual differences in performance exist in natural environments (Cote et al., 2010; Fraser et al., 2001; Hanson et al., 2008, 2010; Taylor and Cooke, 2014), few studies address the relationship between performance and stress-coping behaviours in wild populations.

\subsection{Stress and behaviour}

In addition to performance capabilities, individual differences in endocrine stress responses can also be proximate causes of divergent personalities. Relationships between endocrine reactivity and the consistent stress coping behaviours of individuals suggest that some types of personality are under endocrine control (Koolhaas et al., 1999; Øverli et al., 2005). When an animal's homeostasis is at risk, endocrine responses orchestrate a variety of changes to help the organism cope with stress (Sapolsky et al., 2000), including alterations in behaviour. In fish, these endocrine response systems include the brain-sympathetic-chromaffin cell axis and the hypothalamic-pituitary-interrenal axis (HPI; Wendelaar Bonga, 1997). Catecholamines and corticosteroids are important end- 
products of these axes, which mediate changes in metabolism and ion balance, cardiovascular, respiratory, and immune functions (Barton, 2002) and ultimately induce changes in behaviour (Schreck et al., 1997). The activity of the HPI axis in fishes appears to have a particularly strong relationship with stress coping behaviours, which is consistent with its analogues in other animals (Koolhaas et al., 1999; Øverli et al., 2005).

Despite evidence of a relationship between the activity of the HPI axis and behaviour, only a few studies have tested the causal link between cortisol, the primary glucocorticoid in fish, and styles of stress coping behaviour in isolation from other parts of the HPI axis, such as the perception of a stressor and hormones that stimulate the production of cortisol (Conrad et al., 2011). These include studies that have explored the effects of cortisol on behaviour in fish using exogenous cortisol treatments. This approach initiates the cortisol-mediated responses to stress without activating the onset of the HPI axis and without a sensory perception of a stressor and can thus be used to isolate the cortisolmediated effects on behaviour. Several of these studies provide evidence that cortisol is related to altered behaviour in fish. For example, an intraperitoneal cortisol implant increased the probability of social subordination in juvenile captive bred rainbow trout in size-matched pairs but this effect was abolished with the administration of the glucocorticoid receptor antagonist, RU486 (DiBattista et al., 2005). In another study, a chronic cortisol treatment from an implant resulted in reduced feeding in rainbow trout but did not alter their swimming performance (Gregory and Wood, 1999). Other studies that explore the relationships between specific stressors, physiological measures, and behaviour reveal that there can also be an interaction between stressors and the effects of an individual's metabolism on behaviour (see review in Killen et al., 2013). 


\subsection{The ecological relevance of behavioural studies}

Many of the studies of the physiological mechanisms of personality and stress-coping styles have been conducted on captive-bred animals (Archard and Braithwaite, 2010; Koolhaas et al., 2007) because of the logistical challenges of collecting and housing wild animals. Unfortunately, there are limitations to the generalizations researchers can make about personality in wild populations based on studies of captive-bred animals. These issues are discussed in detail in Archard and Braithwaite (2010) and I summarize them here. Changes in genotype frequencies can occur in captive-bred populations as a result of artificial selection, the relaxation of natural selection, and inbreeding (Woodworth et al., 2002). These changes in selection regimes can lead to alterations in physiological, morphological, and life-history characteristics in captive populations (Huntingford, 2004; McDougall et al., 2006) as well as changes to functional links between different axes of personality and their relationships with other characteristics (Sih et al., 2004; Réale et al., 2007). Developmental effects, environmental effects, and past experiences, such as predation and environmental fluctuations, can also contribute to differences in personality between captive-bred and wild populations (Archard and Braithwaite, 2010; Falconer and Mackay, 1996). For these reasons, researchers interested in the mechanisms and ecological consequences of personality and stress-coping styles should preferentially study these phenomena in wild animals in natural environments.

Investigating the relationships between physiology and personality, as well as the ecological relevance of personality, in wild animals in the laboratory also has important limitations. Findings indicate that interactions between genotypes and environmental conditions can have effects on behavioural phenotypes (Nussey et al., 2007; Dingemanse 
et al., 2009). These observations suggest that animals could modify their behaviour in response to the laboratory environment, making it difficult to predict whether personalities in the laboratory would remain consistent in natural environments. Indeed, a meta-analysis by Bell et al. (2009) indicates that behavioural consistency tends to be greater in the field than in the laboratory. Animals might have higher behavioural consistency in the field as an adaptive response to fluctuating conditions or as a result of environmental constraints. In either case, the results of the study by Bell et al. (2009) suggest that personality in the laboratory might not always be representative of personality in the field. Because of the sensitivity of wild animals, such as fish, to disturbance and environmental conditions, captivity can also be stressful for animals, potentially influencing physiological parameters such as hormone concentrations (Pankhurst, 2011). Thus, stress caused by captivity might also influence physiological measures from wild animals. Despite the challenges of studying wild animals in captivity, captive studies of wild animals continue to be important in behaviour research because they facilitate the study of physiological variables in a controlled environment.

The physiological and ecological relevance of laboratory tests for animal personality and its physiological drivers should be validated if possible. To test whether physiological features, such as hormone levels, are related to personality, these features can be manipulated and their effects on behaviour can be observed (i.e., phenotypic engineering: Ketterson et al., 1996). The ecological relevance of personality in the laboratory would ideally be validated by comparing behaviour in the laboratory to fitness-related behaviour in the field. For example, the behaviour of both great tits (Parus major) and Trinidad killifish (Rivulus hartii) in the laboratory predicted movements in the field (Dingemanse 
et al., 2003; Fraser et al., 2001). However, natural enclosures, although they differ from truly natural environments, could be used to approximate natural conditions and to validate behaviours in the laboratory when tests in the field are not possible.

\subsection{Checkered pufferfish}

Checkered pufferfish (Sphoeroides testudineus) provide a useful model to study whether fish from a fluctuating and potentially stressful environment will demonstrate consistency in behaviour and performance and whether a cortisol treatment will alter this consistency. This species is common throughout the tropical and sub-tropical mangrove habitats (Fig. 1) along the Atlantic coast of the Americas, with populations being found from Florida to Brazil (Shipp, 1974). Checkered pufferfish are well adapted to withstand frequent and drastic changes in temperature (Targett, 1979) and salinity (Contente et al., 2011; VegaCendejas and de Santillana, 2004), and must also withstand frequent natural and anthropogenic alterations to their habitat (Ellison and Farnsworth, 1996). In addition to these environmental stressors, pufferfish are subject to predation by herons (Ardeidae) (Recher and Recher, 1968) and fish (Randall, 1967), despite their defensive toxin, tetrodotoxin (Davis, 1988; Deeds et al., 2008), and their ability to increase their size by pumping water or air into their stomachs (Brainerd, 1994). 


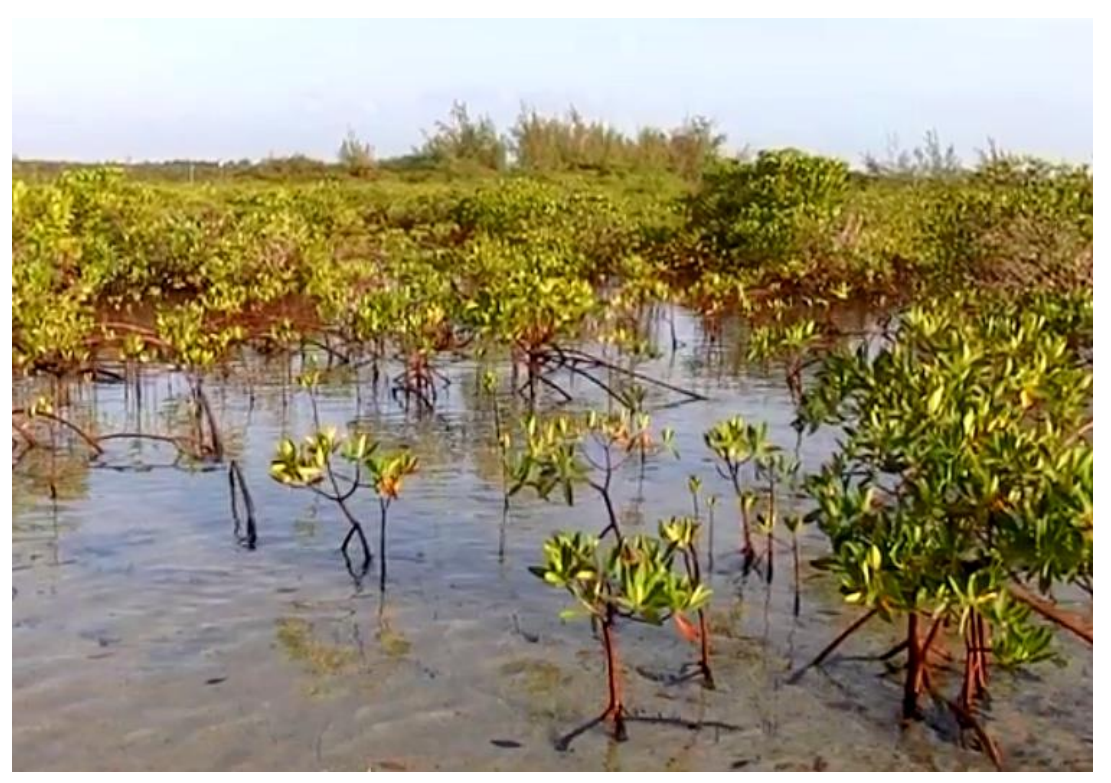

Figure 1. The mangrove swamp surrounding Page Creek in Eleuthera, The Bahamas, at mid-tide.

\subsection{Research objectives}

In this study, I tested whether or not pufferfish exhibit consistent individual-level differences in activity and anti-predator responses (simulated aerial and aquatic predation events), as well as performance under stress (i.e., puff magnitude and duration, duration of a chase to exhaustion) over time. I also tested whether or not individual activity and performance were repeatable between a laboratory environment and a natural, enclosed environment. I conducted a displacement study to determine how behaviour and performance traits correspond to individual differences in movement and recapture in the field. Lastly, I tested whether a cortisol treatment (Fig. 2) would alter individual consistency in behaviour and performance. To do this, I injected the fish with a physiological dose of cortisol for an intermediate duration (3 days) to activate the cortisol-mediated components of the stress response and compared the behaviour and 
performance of individuals before the cortisol treatment, during peak cortisol, and after the cortisol treatment was exhausted.

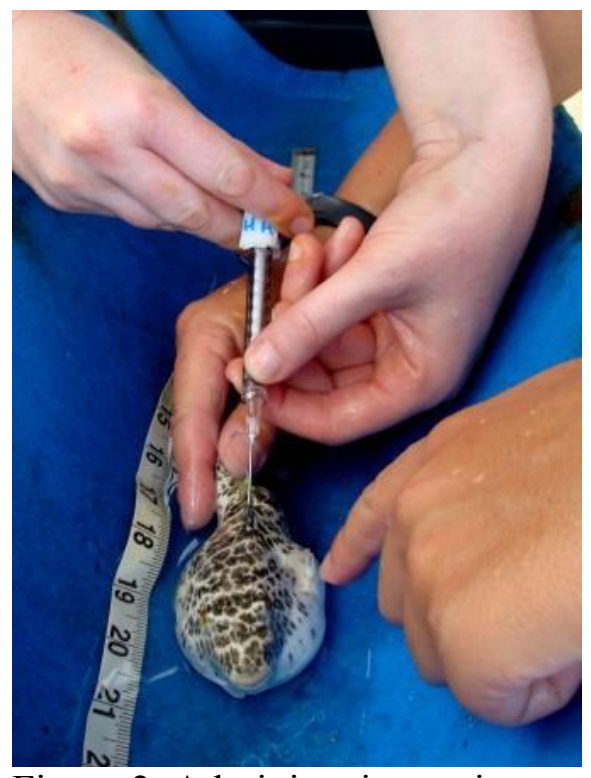

Figure 2. Administering an intramuscular injection of cortisol in a cocoa-butter vehicle to a checkered pufferfish.

\subsection{Significance}

Individual differences are subject to natural selection; for this reason, personalities and stress-coping styles that have fitness consequences may be involved in higher-order ecological and evolutionary processes (Dingemanse and Wolf, 2013). Because of the potential importance of personalities and stress-coping styles in these processes, the proximate causes of personality and their ecological relevance in wild animals are of great interest. My results reveal whether individuals from a habitat where they are subject to environmental fluctuations and predation pressure have consistent activity and threatresponse behaviour, and whether these were correlated with measures of puffing and swimming performance to form coping styles. If personalities are related to performance, this suggests that performance capabilities are involved in shaping personalities. The 
results also provide information as to whether the behaviour and performance of this species in the laboratory are reliable predictors of these characteristics in more natural conditions, and whether they are related to an ecologically relevant behaviour in the field. Furthermore, the experiments give us insight into the endocrine control of behaviour and performance in this species, by revealing how a cortisol treatment was related to performance, activity, and various behavioural responses to stressors. This is among a minority of studies that validate laboratory observations of personality and performance in natural enclosures. It is also one of the few that explores the relationship between experimental observations of personality and performance and ecologically relevant behaviour in the field, as well as the mechanistic relationship between cortisol and personality a wild animal.

\section{Methods}

\subsection{Study site and study animals}

Checkered pufferfish $(n=60$; January 2014) were collected in Page Creek (244'04.7'N, 76² $18^{\prime} 51.6^{\prime \prime} \mathrm{W}$; Fig. 3), a mangrove-lined creek at the south end of Eleuthera, The Bahamas, using a large $(20 \mathrm{~m})$ beach seine during the outgoing tide. Only fish weighing $50 \mathrm{~g}$ and over were retained, to prevent mortality from tagging and cortisol injection procedures. Captured fish were transported to the wetlab research facilities at the Cape Eleuthera Institute $\left(24^{\circ} 50^{\prime} 06.70^{\prime} \mathrm{N}, 76^{\circ} 19^{\prime} 31.69^{\prime \prime} \mathrm{W}\right)$ in coolers with frequent water changes (30\% water volume every 5 minutes) to maintain temperature and aeration. On arrival at the laboratory, fish were all held together in a large circular $1831 \mathrm{~L}$ (33 fish $\mathrm{m}^{-1}$ ) tank until they were marked with individual tags, after which they were 
moved alternately between a $\sim 40 \mathrm{~L}$ rectangular raceway $\left(136\right.$ fish $\left.^{-1}\right)$ and a $\sim 910 \mathrm{~L}$ (66 fish $\mathrm{m}^{-1}$ ) circular tank between behaviour trials. All tanks were supplied with UVtreated flow-through seawater at a temperature was that of ambient coastal conditions $\left(\sim 24^{\circ} \mathrm{C}\right)$. Fish were fed to satiation with chopped sardines (Sardinella aurita) every 2 days. Each fish was tagged for identification using surgical tools, numbered vinyl laminated tags (Floy Tag \& Mfg. Inc., Seattle, WA), and tagging line that were disinfected with diluted povidone-iodine and rinsed in fresh water before use. Each fish had a numbered tag sutured to the caudal peduncle using a reverse cutting needle and 17 lb. fused polyethylene braid (Berkley ${ }^{\circledR}$ Nanofil; Pure Fishing, Inc., Columbia, SC). Fish were not anaesthetized during any procedure because anaesthesia was not needed to immobilize the fish to facilitate handling and prevent harm, and because there is no clear indication that anaesthetization prevents physiological stress responses to handling (Houston et al., 1971; Iwama et al., 1989). All research was conducted in accordance with the guidelines of the Canadian Council on Animal Care as administered by Carleton University (B12-01). 


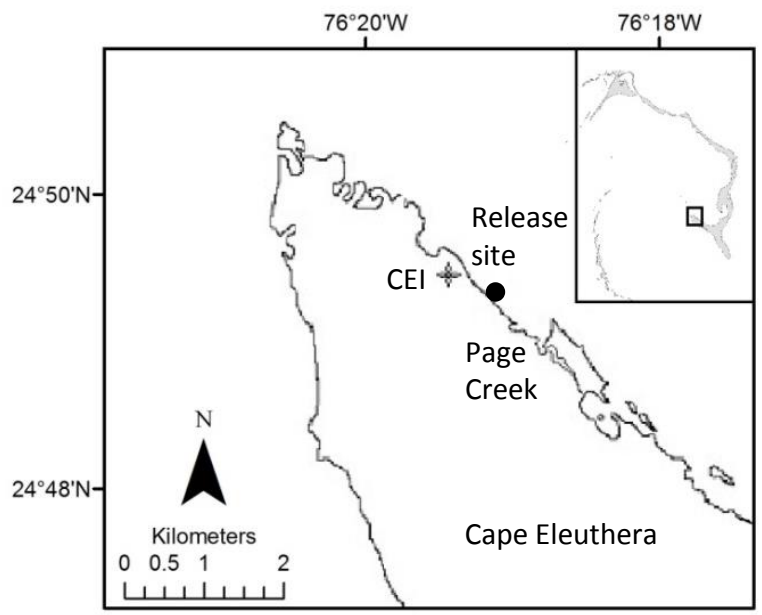

Figure 3. Map of the research sites on Cape Eleuthera, Eleuthera, The Bahamas. Page Creek was the fish collection location. A star indicates the Cape Eleuthera Institute (CEI) and a black circle marks the release site for the displacement experiment. The inset shows Eleuthera with the study region highlighted. This figure is reprinted with the permission of Felicia Cull.

\subsection{Repeatability of behaviour and performance in the laboratory}

The fish were allowed to recover for approximately 24 hours after being tagged before being tested for behaviour and performance, which was considered to be a sufficient recovery period because the cortisol response to handling stress in checkered pufferfish and the aerobic recovery from puffing in the black-saddled pufferfish (Canthigaster valentini) last less than six hours (Cull et al., 2015a; McGee and Clark, 2014). Each fish was individually tested for puff performance, activity, startle duration, and the time it took to chase to exhaustion (swimming performance). Behaviours were recorded for analyses using a camera mounted directly overhead (GoPro HD Hero; GoPro Inc., San Mateo, CA). 
Before being placed in an arena, each fish was air exposed and gently squeezed three times to induce puffing. Puff duration was recorded and the extent of the puff was scored (puff score). To score the extent of the inflation, 0 described no puff, 1 described less than half a full puff, 2 described an intermediate level of inflation, and 3 described a full puff during which the skin was taut and further attempts to inflate by the fish did not increase its volume (Cull et al., 2015a). Puffing is an important performance metric for pufferfish, as it can help these fish avoid consumption by predators after capture (Recher and Recher, 1968).

After scoring the puff, each fish was placed into an individual $30 \times 50 \mathrm{~cm}$ plastic experimental arena with a $10 \mathrm{~cm}$ grid marked on the bottom and filled to a depth of 10 $\mathrm{cm}$ with seawater. The fish were allowed to acclimate to the experimental arena for two minutes before activity was measured. Activity was quantified by counting the number of $10 \mathrm{~cm}$ grid units the fish crossed with the tip of its nose within five minutes. Activity is an ecologically relevant measure which is related to risk-taking and exploration in natural conditions (e.g., Sih et al. 2003; Bell, 2005; Wilson and McLaughlin, 2007).

To simulate a predation threat from above, after determining the position of the fish in the arena, a lead weight held at waist height and tied to a fishing line at the end of a pole was dropped into each arena within the view of the fish and then immediately removed. The weight made both a splash on the surface of the water and a sound as it hit the bottom of the arena. Startle duration was measured as the time required for the fish to resume the same level of swimming activity as that exhibited several seconds prior to the test stimulus. Startle behaviour was distinctive, generally consisting of a brief sprint followed by one or more periods of immobility before resuming prior behaviour, which generally 
consisted of slow swimming around the periphery of the arena. Observations ceased after one minute. The response to a threat from above is a relevant measure of predator evasion behaviour because herons are suspected to be one of the more frequent predators of checkered pufferfish (Recher and Recher, 1968).

After the startle-response test we measured the time required to chase each fish to exhaustion in order to quantify swimming performance. The fish were chased individually by hand within the 30x50 $\mathrm{cm}$ arena until they either puffed or there was no body-flex response after three deliberate, consecutive tail grabs and exposure to air (Thiem et al., 2013). In this way we were able to quantify the swimming endurance of each fish and assess the effect of a cortisol treatment (see below) on the swimming performance. This test has been adapted from other studies that effectively compared the swimming performance of checkered pufferfish (Thiem et al., 2013) as well as other fishes (Heath et al., 1993; Portz, 2007). Each fish was returned to the holding tank at the end of each trial. After the initial trial, these behaviour and performance trials were repeated with the same fish two days later, after an exogenous cortisol treatment, and again once the cortisol treatment was exhausted (see below).

\subsection{Cortisol treatment}

Immediately after the initial set of behaviour trials, all fish were weighed and assigned to two treatment groups, to one of which was administered a physiological dose of cortisol $(\mathrm{n}=32)$, whereas the other group was kept as a control $(\mathrm{n}=28)$. No sham treatment was included in the study because it has been demonstrated that giving checkered pufferfish a sham cocoa butter injection does not cause cortisol levels to differ from minimally 
handled control fish 48 hours after the treatment (Cull et al., 2015b). Furthermore, the stress associated with handling and sham injections in fish has been demonstrated to cause short-term increases in cortisol levels that are intermediate between control individuals and cortisol treated individuals (e.g., O'Connor et al., 2009, 2010, 2011b; Dey et al., 2010). Thus, a sham-treated group would essentially be an acute, intermediate cortisol treatment, and for this reason we chose not to include this treatment in the study. Care was given in assigning fish to treatment groups so that the weight distribution of fish between groups was approximately equal (Mann-Whitney $U=310$, control $\mathrm{n}=28$, cortisol treatment $\mathrm{n}=27, \mathrm{p}=0.26$ two-tailed; fish removed from the study are excluded from this test, see below).

Cortisol treated fish received a heated $50 \mathrm{mg}$ per $\mathrm{ml}$ cortisol (hydrocortisone 21hemisuccinate; Sigma H2882, Sigma-Aldrich, St. Louis, MO) in cocoa butter intramuscular implant from a $1 \mathrm{ml}$ syringe with an 18 -gauge, 2.5 -cm needle. Each treated fish received a $5 \mathrm{ml}$ per $\mathrm{kg}$ body weigh dose to simulate the increase in cortisol experienced after an acute stressor. Cull et al. (2015b) determined that this treatment increases the plasma cortisol of checkered pufferfish to $147 \pm 35 \mathrm{ng} \mathrm{ml}^{-1}$, which is similar to the rise in plasma cortisol to $126 \pm 34 \mathrm{ng} \mathrm{ml}^{-1}$ that they observed in response to an acute stressor. Behaviour trials were repeated for both groups approximately 48 hours after the cortisol implant, when circulating cortisol from the implant had reached its peak (Cull et al., 2015b). Behaviour trials were also repeated four days after the cortisol treatment, when the implant was exhausted (Cull et al., 2015b). 


\subsection{Validation in a natural enclosure}

In July 2014, fish were collected $(\mathrm{n}=99)$, housed, and tagged as described above, with the exception that fish were distributed between two $\sim 440$ L rectangular raceways (112 fish $\mathrm{m}^{-1}$ ) after tagging. Each fish was tested once for puff duration, activity, and swimming performance in the laboratory over the course of two days as described in the first portion of the study at a temperature of approximately $29^{\circ} \mathrm{C}$. In this series of trials the fish were gently squeezed five times before measuring puff duration, to increase the likelihood that individuals would inflate. Two days after the trials in the laboratory, each fish was tested again for puff duration, activity, and swimming performance in a natural habitat over the duration of three days. To do this, fish were transported in a pail of seawater to a nearby wetland mesocosm. The wetland area receives constant seawater input from the wetlab and empties into the ocean. The wetland contains a variety of fish and invertebrate species as well as both red (Rhizophora mangle) and black mangroves (both Avicennia germinans and Halimeda spp.). In this semi-natural habitat the puff duration test was repeated immediately after transport and then each fish was placed in a $35 \times 50 \mathrm{~cm}$ mesh pen with the bottom filled with wetland substrate and a $10 \mathrm{~cm}$ grid marked on the bottom with string. The pens were filled to a depth of $20 \mathrm{~cm}$ with seawater. Activity and swimming performance were measured as described above, with the exception that the number of squares crossed was converted to distance and rounded to the nearest $10 \mathrm{~cm}$ to account for grid squares in the mesh pens that were smaller than $10 \mathrm{~cm}$. Throughout the trials in the mesocosm, temperatures in the pens ranged from $28.2^{\circ} \mathrm{C}$ to $35.2^{\circ} \mathrm{C}$, fluctuations which pufferfish are regularly subject to in tidal creek systems (Shultz et al., 2014). 


\subsection{Recapture Study}

We used a displacement and recapture procedure to test whether behaviour and performance in the laboratory and a natural enclosure were related to whether fish would return to the tidal creek where they were originally captured. Of the fish used to validate performance tests in natural enclosures, 70 fish were released near the shoreline approximately 625 meters up-current from the mouth of Page Creek (2449’16.6”N, $\left.76^{\circ} 19^{\prime} 8.5^{\prime \prime} \mathrm{W}\right)$ in an area with rocky, sandy substrate and no mangroves (Fig. 3). A control group of 20 fish was released in Page Creek. We attempted to recapture fish in Page Creek 2, 3, 19, 20, and 23 days after the initial release using seine nets. Checkered pufferfish are relatively weak swimmers and thus their performance abilities have the potential to predict their ability to swim distances and seek out the desirable Page Creek habitat. Furthermore, more active individuals might be more likely to either to explore their environment and locate the desirable habitat in their original capture creek or to continue to explore the coastline once the creek was found. In the first scenario, more active fish would be more likely to be recaptured in Page Creek, whereas in the second scenario, more active fish would be less likely to be recaptured in Page Creek.

\subsection{Analysis}

Data were analysed using R (Version 3.0.3; R Core Team, 2014) and Sigmaplot (Version 11.0; Systat Software, Inc., 2008). Either Pearson's correlation or Spearman's rank correlation, depending on the distribution of the data, were used to determine whether the behaviours and performance of individual fish were correlated between repeated trials in the laboratory, and between the trials in the laboratory and the natural enclosure. 
The proportion of fish recaptured from the control and displaced groups were compared in Sigmaplot using a chi-square test. Recapture or no recapture of the displaced group in the original capture tidal creek was modeled using a logistic regression with a logit link. A backwards single-term deletion procedure was used to select fixed-effects using likelihood-ratio tests at $\alpha=0.05$ (drop1 command in R) (Chambers, 1992) with puff duration, activity, swimming performance, total length, and Fulton's condition factor as fixed-effects. We tested the linearity of the logit of each factor using the method described in Field et al. (2012). Laboratory and natural enclosure fixed-effects were modelled separately to avoid collinearity. The data was examined for outliers and influential data using the studentized residual, hat values (leverage), and the DFBeta of each case for each predictor.

In the puff duration data, the number of individuals inflated decayed with time (seconds after the beginning of the puff), and there were individuals that did not puff. For these reasons we used the Peto and Peto modification of the Gehan-Wilcoxon test to compare the left-censored puff duration survival curves (cendiff command in R) (Peto and Peto, 1972) between control and cortisol treatments within trials to test the null hypothesis that the survival curves of the two treatments were not different within trials. Using the Cochran-Mantel-Haenszel test for stratified categorical data (mantelhaen.test in R; Cochran, 1954; Mantel and Haenszel, 1959) we tested the null hypothesis that the relative proportions of puff-scores are the same between treatment groups within trials. As the activity data met the assumptions of normality (Shapiro-Wilk test) and heterogeneity (Levene's test), we ran a type III ANOVA on the activity data with subject, treatment, trial, and the interaction between trial and treatment to determine whether there was a 
significant interaction effect. Because there was no interaction effect, we ran a type II ANOVA with subject, treatment, and trial as factors to determine the effects of treatment and trial on activity, using the Greenhouse-Geisser method to correct for sphericity. The number of individuals who continued to express altered behaviour in response to a simulated threat decayed with time (seconds after the threatening event) and observations ended 60 seconds after the threat. For these reasons we used a log-rank test to compare all the right-censored survival curves of startle behaviour duration of the two treatments within trials. If the curves of cortisol and control treatments differed significantly from each other, the curves were compared using a log-rank test within treatments between trials and within trials between treatments to determine which factor was the source of the difference. A log-rank test was also used to compare the survival curves of the time to chase a fish to exhaustion with treatment and trial as factors. If the observed data from the two treatments differed significantly from each other, the curves were compared within trial by treatment and among trials. To determine whether any of the behaviours measured formed syndromes or stress-coping styles, we used Spearman's rank correlation to quantify the relationships between behaviours and performance. In the event of fish mortality (January, $n=5$ ), such individuals were removed from the full dataset and not included in the analyses.

\section{Results}

\subsection{Behavioural correlations}

All behaviours had at least one highly significant correlation between two trials (Table 1 and 2), with the exception of the correlation between activity in the laboratory and the 
field in July $(r=0.091, \mathrm{n}=90, \mathrm{p}=0.39)$. Fulton's condition factor was significantly correlated with activity in the initial trial $(r=0.47, \mathrm{n}=55, \mathrm{p}=<0.001)$ and with swimming performance in the trial after cortisol had been exhausted $(\rho=-0.32, \mathrm{n}=55, \mathrm{p}$ $=0.02)$ in the January lab tests. Rank total length was significantly correlated with rank puff duration in the natural enclosure $(\rho=-0.21, \mathrm{n}=89, \mathrm{p}=0.04)$. Rank puff duration $(\rho$ $=0.225, \mathrm{n}=90, \mathrm{p}=0.03)$ and activity $(r=0.52, \mathrm{n}=90, \mathrm{p}=<0.001)$ in the natural enclosures were correlated with water temperature, but swimming performance was not $(r=0.163, \mathrm{n}=90, \mathrm{p}=0.125)$. The individuals differed from each other in their mean measures of behaviour, in some cases quite distinctly, as indicated by the ranges of the individual mean measures of behaviours in January (Table 3). There was no significant correlation between different behaviours or performance metrics. 
Table 1. Correlations between repeated measures of behaviour of checkered pufferfish in the laboratory (January) between an initial trial (initial), a trial at peak cortisol levels (peak cortisol), and a trial after the cortisol treatment had been exhausted (post cortisol).

\begin{tabular}{|c|c|c|c|c|c|}
\hline $\begin{array}{l}\text { Pearson } \\
\text { correlation }\end{array}$ & Behaviour & $\begin{array}{l}\text { Trial } \\
\text { comparison }\end{array}$ & $\mathrm{n}$ & $\begin{array}{c}\text { Correlation } \\
\text { coefficient } \\
r\end{array}$ & $\mathrm{p}$-value \\
\hline & activity & $\begin{array}{l}\text { initial/peak cortisol } \\
\text { peak/post cortisol } \\
\text { initial/post cortisol }\end{array}$ & $\begin{array}{l}55 \\
55 \\
55\end{array}$ & $\begin{array}{l}0.326 \\
0.444 \\
0.238\end{array}$ & $\begin{array}{r}0.02 \\
<0.001 \\
0.08\end{array}$ \\
\hline \multirow[t]{5}{*}{$\begin{array}{l}\text { Spearman } \\
\text { rank } \\
\text { correlation }\end{array}$} & Behaviour & $\begin{array}{l}\text { Trial } \\
\text { comparison }\end{array}$ & $\mathrm{n}$ & $\rho$ & $\mathrm{p}$-value \\
\hline & puff duration & $\begin{array}{l}\text { initial/peak cortisol } \\
\text { peak/post cortisol } \\
\text { initial/post cortisol }\end{array}$ & $\begin{array}{l}55 \\
55 \\
55\end{array}$ & $\begin{array}{l}0.166 \\
0.374 \\
0.339\end{array}$ & $\begin{array}{r}0.23 \\
0.005 \\
0.01\end{array}$ \\
\hline & $\begin{array}{l}\text { duration of } \\
\text { startle response }\end{array}$ & $\begin{array}{l}\text { initial/peak cortisol } \\
\text { peak/post cortisol } \\
\text { initial/post cortisol }\end{array}$ & $\begin{array}{l}54 \\
54 \\
53 \\
\end{array}$ & $\begin{array}{r}-0.0561 \\
-0.146 \\
0.292 \\
\end{array}$ & $\begin{array}{l}0.69 \\
0.29 \\
0.03\end{array}$ \\
\hline & $\begin{array}{l}\text { time to } \\
\text { exhaustion }\end{array}$ & $\begin{array}{l}\text { initial/peak cortisol } \\
\text { peak/post cortisol } \\
\text { initial/post cortisol }\end{array}$ & $\begin{array}{l}54 \\
55 \\
54 \\
\end{array}$ & $\begin{array}{l}0.158 \\
0.363 \\
0.126 \\
\end{array}$ & $\begin{array}{r}0.25 \\
0.007 \\
0.36 \\
\end{array}$ \\
\hline & puff score & $\begin{array}{l}\text { initial/peak cortisol } \\
\text { peak/post cortisol } \\
\text { initial/post cortisol }\end{array}$ & $\begin{array}{l}55 \\
55 \\
55\end{array}$ & $\begin{array}{l}0.271 \\
0.411 \\
0.333\end{array}$ & $\begin{array}{r}0.05 \\
0.002 \\
0.01\end{array}$ \\
\hline
\end{tabular}


Table 2. Correlations between repeated measures of behaviour of checkered pufferfish in the laboratory and in a natural enclosure (July).

\begin{tabular}{llrrr}
\hline & Behaviour & $\mathrm{n}$ & \multicolumn{1}{c}{$\begin{array}{l}\text { Correlation } \\
\text { coefficient }\end{array}$} & \multicolumn{2}{c}{$\mathrm{p}$-value } \\
\hline Pearson correlation & activity & 90 & 0.0914 & 0.39 \\
& chase to exhaustion & 88 & 0.335 & 0.001 \\
\hline Spearman rank correlation & puff duration & 90 & 0.297 & 0.005 \\
\hline
\end{tabular}

Table 3. Medians and ranges of the mean values of behaviours measured within individual checkered pufferfish (January).

\begin{tabular}{lrl}
\hline Behaviour & Median & Range \\
\hline Puff duration $(\mathrm{sec})$ & 0.7 & $0-6$ \\
Puff score $(1-3)$ & 0.7 & $0-2.7$ \\
Activity $(10 \mathrm{~cm}$ units) & 246 & $56-388$ \\
Time to exhaustion $(\mathrm{sec})$ & 105 & $25-689$ \\
Startle duration $(\mathrm{sec})$ & 23 & $2.7-$ censored at 60 seconds \\
\hline
\end{tabular}

\subsection{Recapture}

We recaptured $58 \%$ of the 70 displaced fish and $80 \%$ of the 20 control fish released in the tidal creek of original capture. However, power was low at $\alpha=0.05(0.27)$ and we did not detect a significant difference between the proportion of displaced and control fish that were recaptured $\left(\chi^{2}(1)=1.973, p=0.16\right)$. Only total length was a significant predictor of recapture in the original creek of capture in both models, with longer fish being more likely to be recaptured. Neither behaviour nor performance metrics in the laboratory and in a natural enclosure could be included in the models (Fig. 4, Tables 4 and 5). 

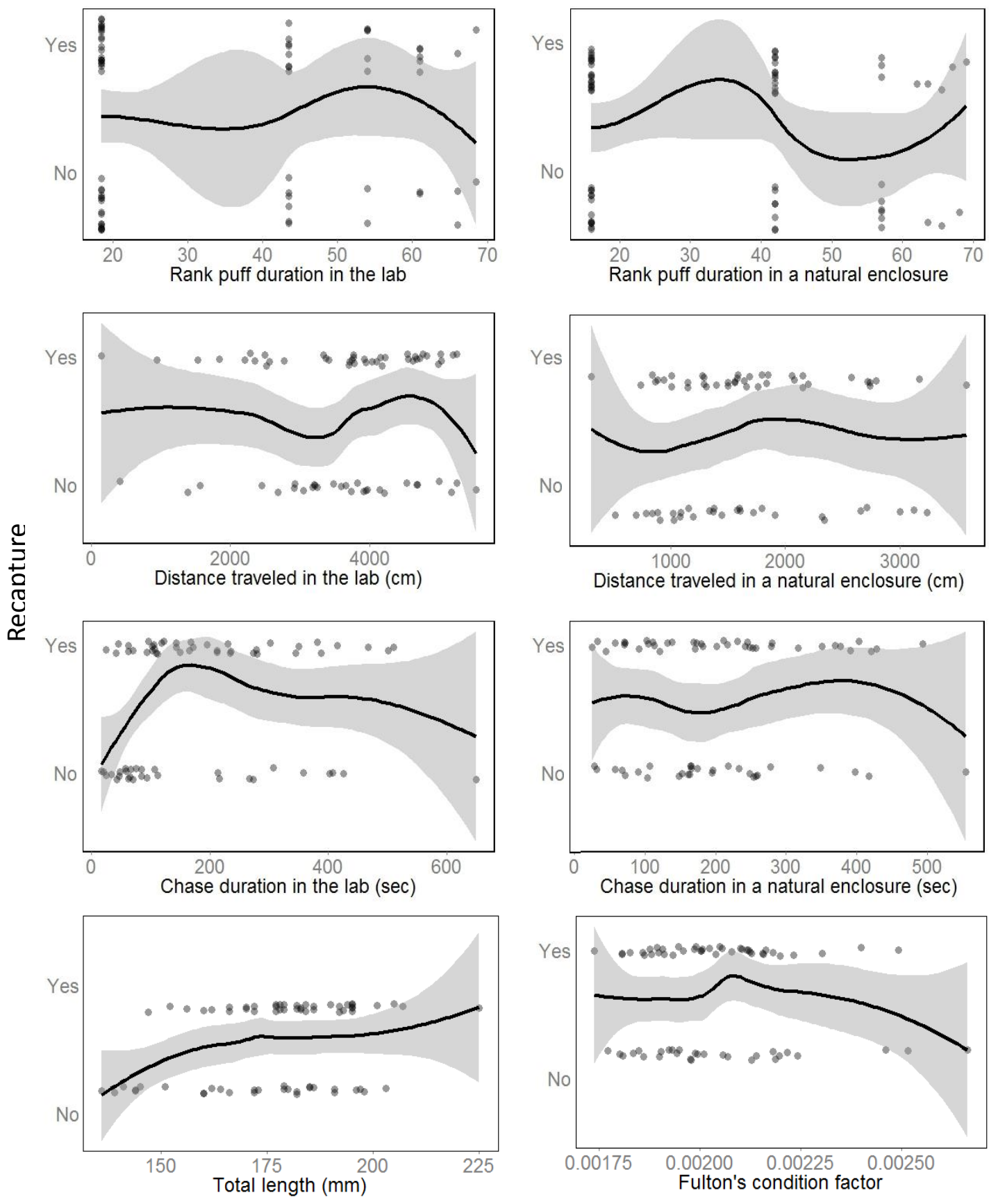

Figure 4. The behaviour and performance of individual checkered pufferfish in laboratory arenas and natural enclosures categorized by capture success in their original tidal creek. Fish were recaptured 2, 3, 19, 20, and 23 days after being displaced $\sim 625 \mathrm{~m}$ up-current along the coast. The black line represents the local regression and the $95 \%$ confidence interval is shaded in grey. Data points have been spaced vertically to reduce overlap 
Table 4. Summary of the terms included in the full model used to predict recapture of checkered pufferfish based on total length, body condition (Fulton's K), puff duration, locomotor activity, swimming performance (time to exhaustion) in the laboratory.

\begin{tabular}{lrcr}
\hline Model term & $L$-ratio & Df & p-value $\left(\chi^{2}\right)$ \\
\hline Total length & 7.360 & 1 & 0.007 \\
Fulton's K & 0.003 & 1 & 0.96 \\
Puff duration & 0.139 & 1 & 0.41 \\
Activity & 0.0365 & 1 & 0.95 \\
Time to exhaustion & 1.533 & 1 & 0.12 \\
\hline
\end{tabular}

Table 5. Summary of the terms included in the full model used to predict recapture of checkered pufferfish based on total length, body condition (Fulton's K), puff duration, locomotor activity, and swimming performance (time to exhaustion) in a natural enclosure.

\begin{tabular}{lrcr}
\hline Model term & $L$-ratio & Df & p-value $\left(\chi^{2}\right)$ \\
\hline Total length & 6.236 & 1 & 0.01 \\
Fulton's K & 0.004 & 1 & 0.95 \\
Puff duration & 0.106 & 1 & 0.60 \\
Activity & 0.246 & 1 & 0.92 \\
Time to exhaustion & 0.0948 & 1 & 0.62 \\
\hline
\end{tabular}

\subsection{Cortisol treatment effects}

There was no significant difference between the puff duration of the cortisol treated fish and the control fish within trials $\left(\chi^{2}=5.8, \mathrm{df}=5, \mathrm{p}=0.322\right)$ (Fig. 5). In addition, there was no significant difference between the puff scores of the cortisol treated group and the control group within trials $\left(\chi^{2}=2.76, \mathrm{df}=3, \mathrm{p}=0.430\right)$. The cortisol treatment did not have any significant effect on activity relative to the control group $(\mathrm{F}=2.11, \mathrm{df}=53, \mathrm{p}=$ 0.151 , ges $=0.021$; Fig. 6 ), whereas the trial repetition did have a significant effect on activity $(\mathrm{F}=65.1, \mathrm{df}=106, \mathrm{GG} \mathrm{p}=<0.001$, ges $=0.357)$. The duration of startle behaviour of the cortisol treated fish did not differ significantly from that of the control group within each trial $\left(\chi^{2}=8, \mathrm{df}=5, \mathrm{p}=0.156\right.$; Fig. 7). In the control group, the 
proportion of fish that remained startled for at least 60 seconds increased with each successive trial. In the cortisol treated group, the proportion of fish that remained startled at 60 seconds decreased between the initial trial and the trial at peak cortisol and subsequently increased to an intermediate proportion during the trial in which the cortisol treatment was exhausted. There was no significant difference in the time to chase a fish to exhaustion between the cortisol and control treatments within the initial $\left(\chi^{2}=0.03, \mathrm{df}=\right.$ $1, \mathrm{p}=0.913)$, peak cortisol $\left(\chi^{2}=0.1, \mathrm{df}=1, \mathrm{p}=0.761\right)$, and post cortisol trials $\left(\chi^{2}=1.5\right.$, $\mathrm{df}=1, \mathrm{p}=0.215$; Fig. 8$)$, but there was a significant difference between trials $\left(\chi^{2}=25.2\right.$, $\mathrm{df}=2, \mathrm{p}=<0.001)$ 

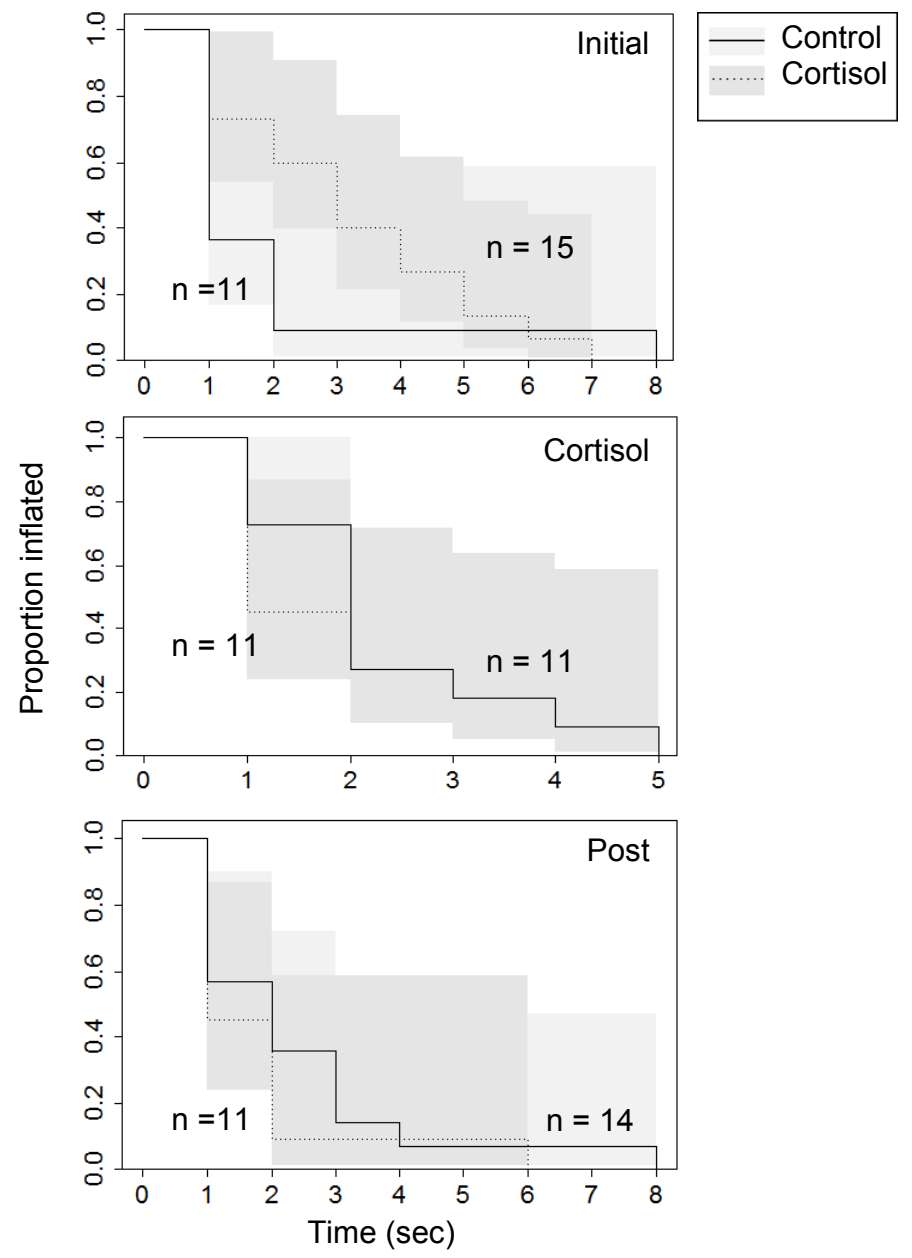

Figure 5. Survival curves of the puff duration of checkered pufferfish. This test was repeated before treatment (Initial), when the cortisol treated group was experiencing peak circulating cortisol (Cortisol) at 48 hours, and after the cortisol treatment had been exhausted (Post) at 4 days. Shaded areas represent the 95\% confidence interval. 


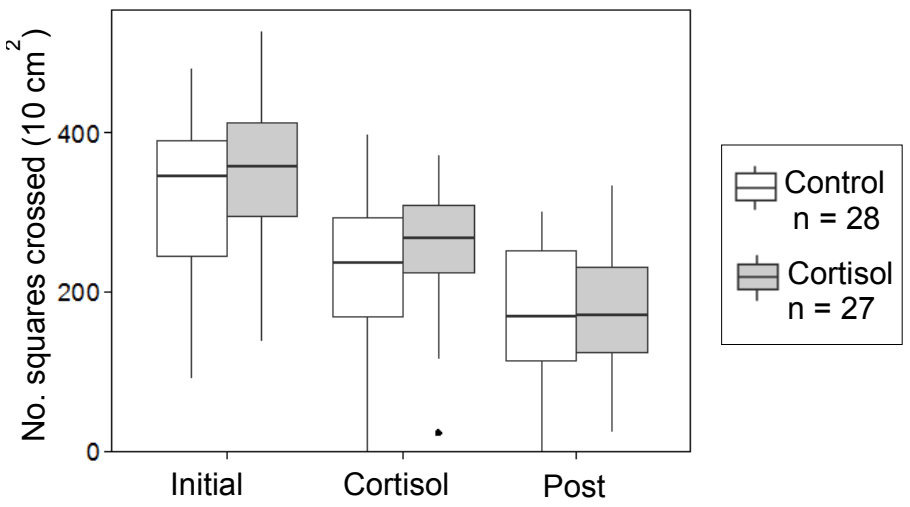

Figure 6 . The number of $10 \mathrm{~cm}$ squares crossed by checkered pufferfish from control and cortisol treated groups during the initial trial (Initial), when cortisol was elevated in the treatment group (Cortisol) at 48 hours, and when cortisol levels had returned to baseline (Post) at 4 days. 

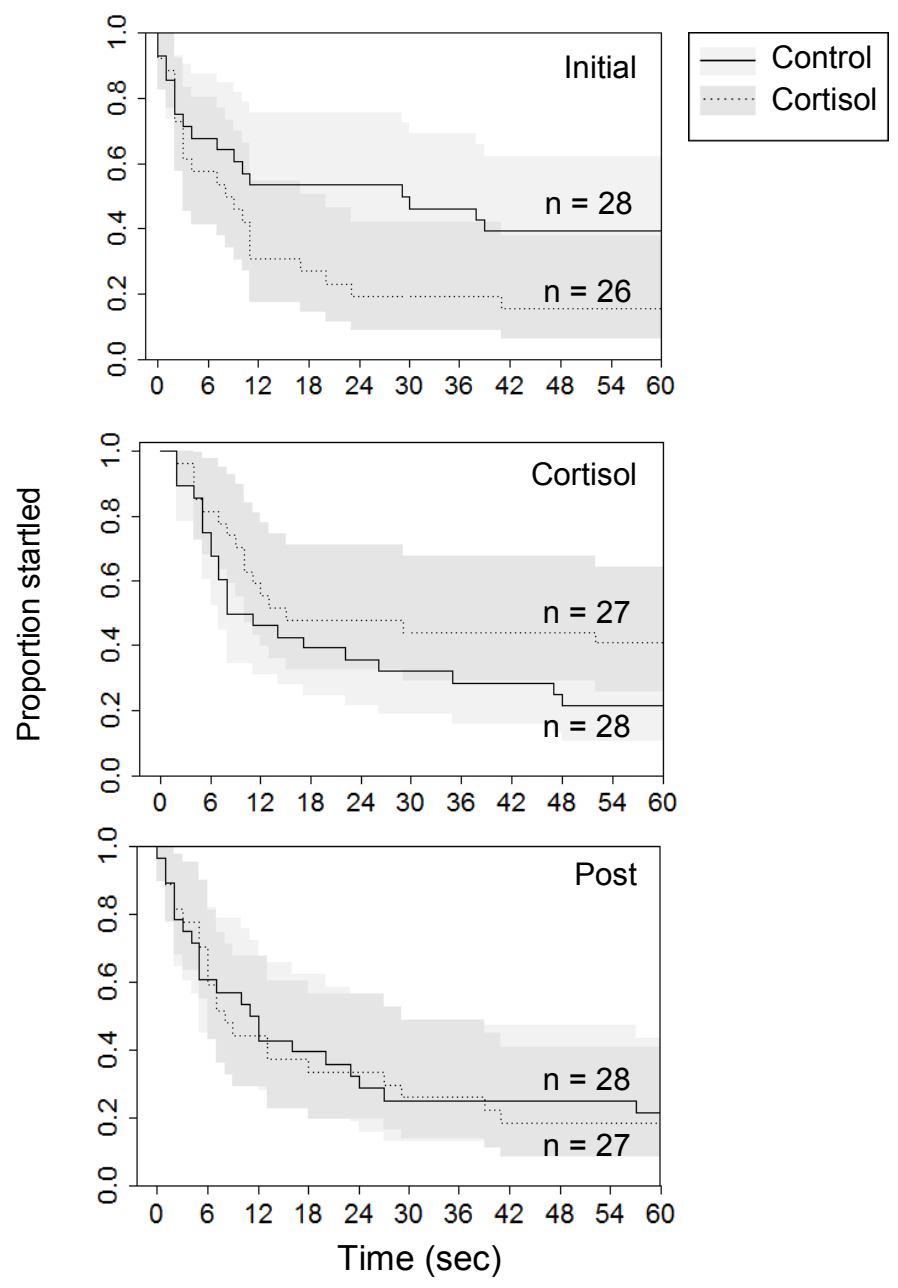

Figure 7. Survival curves of the proportion of checkered pufferfish displaying startled behaviour after a weight was dropped and removed from their individual tanks. This test was repeated before treatment (Initial), when the cortisol treated group was experiencing peak circulating cortisol (Cortisol) at 48 hours, and after the cortisol had returned to baseline (Post) at 4 days. The data was censored after 60 seconds. Shaded areas represent the $95 \%$ confidence interval. 

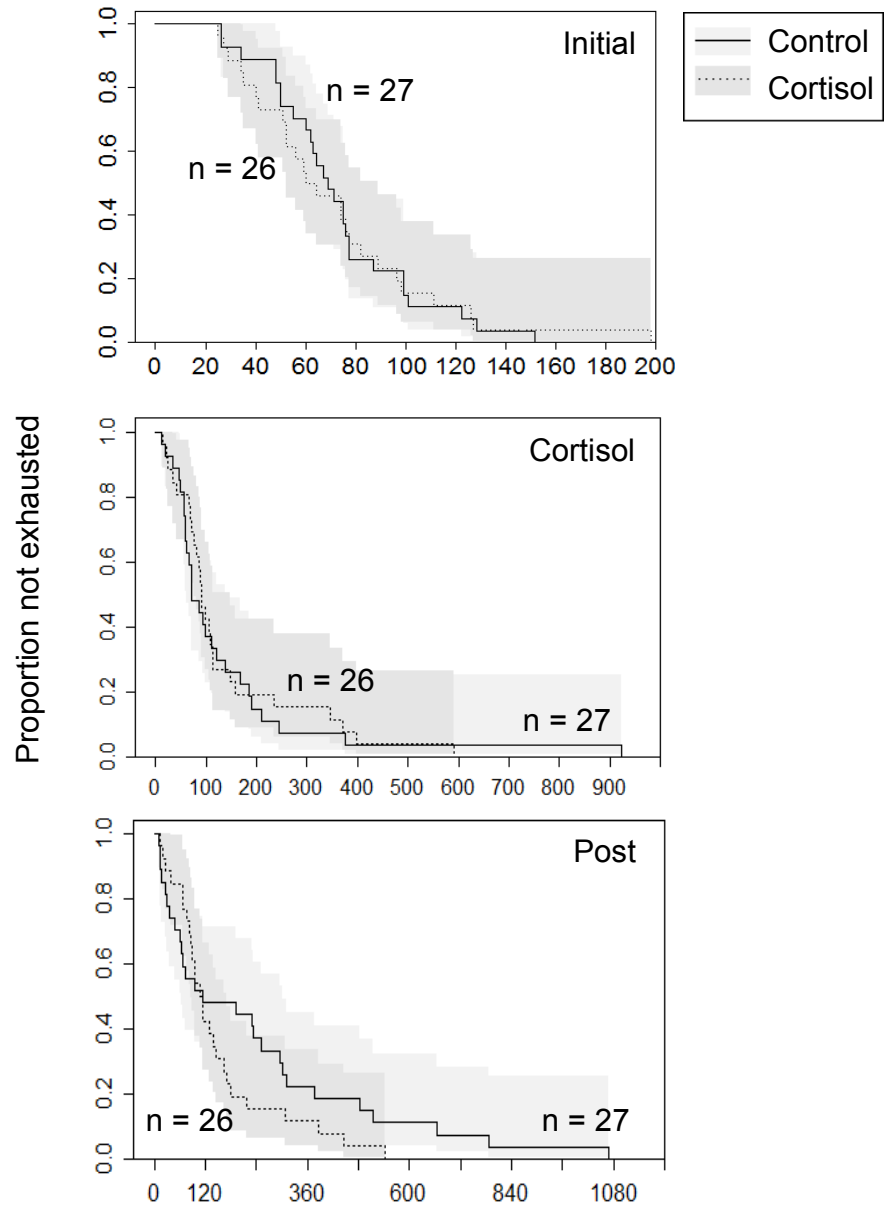

Figure 8. Survival curves of duration of a chase to exhaustion. This test was repeated before treatment (Initial), when the cortisol treated group was experiencing peak circulating cortisol (Cortisol) at 48 hours, and after the cortisol had returned to baseline (Post) at 4 days. Shaded areas represent the 95\% confidence interval.

\section{Discussion}

Our results indicate that checkered pufferfish have consistent individual-level differences in behaviour and performance over time with respect to puff score, puff duration, activity, startle duration, and swimming performance. However, we did not observe any significant correlations between different personality traits, which indicate that the behaviours tested do not form behavioural syndromes in these fish. Neither were there correlations between personality and performance traits, which suggest that these 
individual characteristics do not combine to form coping styles. The puffing and swimming performance of individual fish were also consistent between trials in the laboratory and in a natural enclosure. However, individual differences in these behaviours and performance were not related to whether a displaced fish was recaptured in the original capture creek. In addition, a physiological dose of cortisol did not have a significant effect on any of the consistent behaviours or performance measured either at peak cortisol or after the cortisol treatment was exhausted, with the possible exception of the duration of a startle response.

\subsection{Personality}

Our study demonstrates that pufferfish exhibit consistent within- and between-individual differences in behaviour (i.e., personality). We recognize that the range of behaviours observed may not be representative of the entire population because individuals with certain personality traits are likely to be more catchable by seining than others (e.g., Wilson et al., 2011). Nevertheless, our findings suggest that the personality traits measured persist in a wild population from a variable and physiologically challenging environment. Consistency in behaviour is potentially adaptive under such conditions. For example, personality can be beneficial in circumstances in which the environment changes rapidly and there is a time lag in adaptive population-level responses (DeWitt et al., 1998) or if errors are likely to be made in judging environmental cues, particularly when such errors are costly (Sih, 1992). Diverse personalities might persist because they increase the likelihood that adaptive traits will be present in at least some of the members of the population when conditions change (de Jong and Gavrilets, 2000), or as a result of frequency-dependent selection (Dall et al., 2004). 
Although individuals had consistent differences in behaviour in this study, certain behaviours changed over successive trials for both treatment groups. Activity declined over successive trials, which is a possible indication of habituation to the experimental arena, or may have been caused by the accumulating effects of captivity on the fish. The duration of a chase to exhaustion increased over successive trials, which may have been the result of increased energy availability as a result of regular feedings. It may also be that, although efforts were made to chase the fish as vigorously as possible, changes in the motivation to swim contributed to longer chases. For example, other studies have found that some lizards do not exhibit maximum performance even in challenges such as predator evasion (Irschick and Garland, 2001; Braña, 2003; Irschick, 2003; Irschick et al. 2005; Husak, 2006; Husak and Fox, 2006). It is possible that, after having already survived several similar chases, pufferfish were progressively less motivated to swim at their maximum capacity to evade capture and thus swam more slowly for a longer duration.

\subsection{Behavioural syndromes and stress-coping styles}

We did not observe correlations between different consistent behaviours (i.e., behavioural syndromes) or relationships between performance in response to a threat or a cortisol treatment and consistent behaviour (i.e., coping styles). Although other researchers have found evidence of a mechanistic link between cortisol and behaviour in some fish species (e.g., DiBattista et al., 2005; Gregory and Wood, 1999; Øverli et al., 2005), others studies, including the present study, did not reveal such a link between acute elevations of cortisol and changes in behaviour (e.g., Hosoya et al., 2008; Øverli et al., 2002a; Silva et al., 2010). The lack of behavioural syndromes and stress-coping styles might be adaptive 
in terms of avoiding additional potential constraints on an individual's behavioural response to environmental fluctuation (Sih et al., 2004); however, this notion is in need of further research (see section 5.5).

\subsection{Relationships between behaviour, performance, and intrinsic characteristics}

Whereas swimming and puffing performance were not related to other behaviours measured, we did observe relationships between both body condition and total length, and behaviour and performance. Activity had a positive relationship with body condition in the initial trial. It might be that fish in better condition had more energy available for swimming and were more motivated to actively explore a novel environment but that this motivation decreased as the fish became familiar with the test arena. The negative relationship between body condition and swimming performance in the trial after cortisol had been exhausted is counter-intuitive, as one would expect fish in better condition to have greater swimming endurance. It may be that fish with greater body condition had more robust sprints in response to a threat but tired quickly during the chase, whereas fish with lower condition swam more slowly to conserve energy and were thus able to swim for a longer period, although we were unable to test these explanations in the current study.

Fish size was also related to performance and behaviour in our study. Total length had a negative relationship with puff duration in the natural enclosure. This differs from the results of another study that found that the weight of checkered pufferfish was positively related to puffing performance (Cull et al., 2015a). This difference in relationship between puff duration and fish size may have been caused by context-specific effects on 
puffing, although we can only speculate as to the cause of those effects. In the current study, longer fish were more likely to be recaptured in the original capture creek after displacement. It may be that, although we did not observe a relationship between length and swimming performance during a chase to exhaustion in captivity, there was a relationship between length and swimming ability or motivation in the field. Also, despite efforts to capture all the pufferfish in Page Creek during seining, some fish were able to avoid capture by hiding among the mangrove roots. It could be that certain fish, such as smaller individuals, were less catchable. Other intrinsic factors such as sex and ontogeny may have contributed to individual differences in personality and performance (e.g., Schürch and Heg, 2010a,b; Budaev et al., 1999), but these characteristics cannot be reliably identified in checkered pufferfish without sacrificing them.

\subsection{Relationships between behaviour, performance, and external conditions}

An important consideration for interpreting the results of the current study and comparing them to others is the effects of the environmental context, such as captivity, on fish behaviour and performance in general and on the behavioural response to elevated plasma cortisol. For example, rainbow trout bred for a high cortisol response to confinement-stress showed higher levels of activity in the presence of an intruder than those bred for a low cortisol response to confinement-stress, but not in isolation (Øverli et al., 2002b), revealing how external context can effect behaviour. Captivity can be a chronic stressor for wild fish (Portz et al., 2006) and might have led to desensitization towards cortisol in our study fish (Barton et al., 1987). However, baseline cortisol levels measured in captive checkered pufferfish resemble baseline levels sampled from checkered pufferfish in the field (Jennifer Magel, Carleton University, unpublished data 
in Cull et al., 2015a), which suggests that captivity does not induce chronic increases in cortisol levels in these fish.

Despite evidence that suggests that pufferfish can breathe during inflation (black-saddled pufferfish; McGee and Clark, 2014), results from several studies suggest that the exertion related to inflation, including activity prior to capture, inflation, and potentially energy required keep sphincters closed to maintain inflation, can cause fatigue. Cull et al. (2015a) found that puffing and bite performance declined in checkered pufferfish after an initial stressor combined with puffing. Similarly, Brainerd (1994) observed that longspined porcupinefish (Diodon holocanthus), a relative of the pufferfishes, were unable to inflate after three to eight successive inflations. In addition, McGee and Clark (2014) discovered that oxygen debt persisted in black-saddled pufferfish for an average 5.6 hours post-inflation. The results from these studies suggest that puffing causes fatigue in pufferfish and this may have had an impact on performance and behaviour measured immediately afterwards, especially compared the fish that did not puff. We recommend that future studies on pufferfish behaviour and physiology avoid inducing puffing prior to testing other parameters, unless the objective is to study these responses during fatigue, and that fish be allowed to recover at least six hours between puffing trials.

\subsection{Cortisol effects}

A stress response incorporates a suite of endocrine and other physiological changes and it is possible that cortisol must act in combination with these processes in order to affect changes in behaviour and performance. For example, Øverli et al. (2005) posit that the high levels of corticotropin releasing hormone in fish with a high cortisol response to stress contributes to their high levels of activity. There are also studies which suggest that 
baseline or chronic elevations of cortisol have a greater effect on behaviour and performance than an acute rise in cortisol (Øverli et al., 2002a; Hosoya et al., 2008; Silva et al., 2010), including another study on checkered pufferfish, which revealed that puff score and duration were not related to stress-induced cortisol levels but that puff score might be related to baseline cortisol (Cull et al., 2015a). It is possible that long term exposure to cortisol has implications for behaviour and performance that short-term exposure does not, such as the effects of energy depletion on energetically demanding behaviours (Mommsen et al., 1999).

A general lack of effect by cortisol implants could indicate that this hormone is not involved in the regulation of the traits measured in our study. For example, studies on other fishes have found that individual cortisol levels were not related to behavioural responses to a predator cue (Bell et al., 2007), swimming performance (Gregory and Wood, 1999; Lankford et al., 2005; Cull et al., 2015b) and activity (Farwell et al., 2014; Øverli et al., 2002b; Schjolden et al., 2006). As such, certain behaviours might in fact be more tightly associated with other physiological factors such as circulating levels of catecholamines (Bell et al., 2007).

Puff duration is a possible exception in that there may have been an effect of the cortisol treatment. Although there was no significant difference between the puff duration of the cortisol treated and control groups, there were distinct changes between trials in the proportions of fish that remained inflated for 60 seconds within each treatment, and these changes may be biologically significant. It is possible that energy stores had been depleted in the cortisol treated fish at peak cortisol, reducing their ability to respond to a threat. However, results from a study by Cull et al. (2015b) revealed that an exogenous 
cortisol treatment did not raise blood glucose levels in checkered pufferfish, which casts doubt on this explanation. Alternately, rises in circulating glucocorticoids that exceed acute timescales may suppress behavioural responses to a threat through other pathways. The increasing duration of startled behaviour in the control treated fish over time may be the result of captive conditions; for example, greater densities of fish in captivity relative to the field may increase aggression between fish over time and cause individuals to be more sensitive to threatening stimuli. Another possible explanation is that frequent feeding in captivity gives fish the opportunity to store energy and thus they have more energy available at each successive trial for longer responses to a threat.

\section{Future Directions}

Although pufferfish demonstrated personality and consistent individual-level differences in performance in this study, these characteristics were not correlated with each other and were not related to cortisol levels or movements in the field, despite evidence of such associations in other teleosts (Cote et al., 2010; Fraser et al., 2001; Huntingford et al., 2010; Øverli et al., 2005). These results reinforce the notion that the proximate causes and ecological relevance of personality in animals can be complex and context specific (Dingemanse et al., 2009; Killen et al., 2013). Based on these insights, I offer some methodological considerations for future studies of the hypothalamic-pituitary-adrenal (HPA) and HPI axes. I also expand on my earlier suggestion that measures of performance (e.g., bite force, sprint speed, endurance) be used to link the effects of other physiological characteristics to behaviour. I discuss how to resolve some of the challenges of studying personality and coping styles in heterogeneous environments by 
incorporating measures of plasticity within a study. Based on these suggestions, I give examples of future directions for studying the relationship between personality, plasticity, fitness, and natural selection. I discuss how these approaches could be used to contribute to the conservation of wild populations.

\subsection{Methodological considerations for studies on glucocorticoids}

Additional refinements of the methods used to study the effects of glucocorticoids in vivo could help elucidate the relationships between the HPA and HPI axes, performance, and personality. Glucocorticoid administration is a useful tool because researchers can use it to test the mechanistic effects of glucocorticoids on behaviour and performance. Other methods for examining the effects of glucocorticoids on behaviour, such as observing the characteristics of individuals with different endogenous glucocorticoid levels and testing animals that are the product of selective breeding for glucocorticoid responses, are not well suited to testing the mechanistic effects of glucocorticoids because endogenous levels of these hormones tend to be linked to other physiological traits (Øverli et al., 2005).

In future studies, glucocorticoid treatments should be validated for the species of interest so that they are more likely to elicit natural responses. Generally, dose amounts are chosen to resemble glucocorticoid responses to handling, as in this study. Stress responses to handling are considered to be similar to those in response to attempted predation events, but such events are likely to be rare in nature. Studies using exogenous glucocorticoid manipulation would be more ecologically relevant if they tested a range of doses that reflect physiological responses to stressors of a variety of severities. Dose sizes 
can be validated with relative ease by sampling the plasma glucocorticoid levels of animals at several time points after a disturbance.

Currently, little is known about the temporal patterns of glucocorticoid levels in wild animals in the field. There is evidence that some animals express chronic elevations of glucocorticoids in response to frequent stressors (e.g., snowshoe hares (Lepus americanus); Boonstra et al., 1998; Sheriff et al., 2011), whereas others appear to be subject only to acute rises in glucocorticoids following a stressor (e.g., elk (Cervus elaphus); Creel et al., 2009). Unfortunately, replicating the temporal pattern of glucocorticoid release can be challenging given the technologies available for glucocorticoid administration (Gamperl et al., 1994). Ideally, future studies would choose or develop a glucocorticoid vehicle that releases the hormone in a temporal pattern that approximates the pattern of a glucocorticoid response of that animal in a natural habitat, such as mini-osmotic pumps (Gamperl et al., 1994). Researchers studying chronic glucocorticoid treatments should also assess the effects of habituation, using techniques such as the dexamethasone suppression test (e.g., as used in mammals; Boonstra et al., 1998; Sapolsky, 1983). Habituation to elevated levels of glucocorticoids can affect the sensitivity of that individual to subsequent stressor or repeated increases in glucocorticoids (McCormick et al., 1998; Barton et al., 1987) and thus affect experimental outcomes.

Baseline glucocorticoid levels, rather than acute, stress-induced levels, might be related to stress-coping behaviour in some species (Cull et al., 2015a; Koolhaas et al., 1999; Hosoya et al., 2008; Øverli et al., 2002a; Silva et al., 2010). Because manipulating baseline glucocorticoids with exogenous treatments can be challenging (Gamperl et al., 
1994), researchers may choose to compare individual differences in baseline levels of endogenous glucocorticoids with response variables of interest (e.g., fitness; Bonier et al., 2009). Studies of the behaviour of wild species that can be quickly caught and sampled, or sampled with minimal disturbance (e.g., measuring faecal glucocorticoid metabolite levels), might be more informative than studies measuring baseline glucocorticoid concentrations in wild animals within laboratory contexts because laboratory conditions can induce chronic stress (Pankhurst, 2011). Breeding animals for their baseline glucocorticoid levels and observing correlated traits is also a possibility (e.g., as has been done with rainbow trout, Øverli et al., 2005), but this approach is subject to a number of limitations for the reasons discussed in the introduction.

Some of the limitations of the frequently used methods for determining endogenous glucocorticoid levels might account for the mismatch between these levels and other observed traits; for this reason, I recommend that researchers sample a variety of indicators of endogenous glucocorticoid responses, if possible. For example, concentrations of glucocorticoid metabolites in faeces are commonly used as a noninvasive method to compare blood concentrations of glucocorticoids among individuals. However, diet can alter both the way in which glucocorticoids are metabolized and the bulk of faeces, both of which can alter the concentration of glucocorticoid metabolites (Goymann, 2012). Blood samples can also be taken to assess endogenous glucocorticoid levels, but, as with faecal samples, plasma glucocorticoid levels do not provide information as to whether the glucocorticoid is biologically active, the distribution or abundance of receptors on tissues, the activities of feedback systems, or the responses of target tissues (Williams, 2008; Malisch et al. 2008). There are a number of other ways in 
which baseline and stress induced activities of the HPA and HPI axes and the response of target tissues can be measured, including changes in levels of corticosteroid binding globulin, the dexamethasone suppression test, changes in glucose levels, and free fatty acid levels, as well as glucocorticoid metabolites in faeces, urine, hair, and potentially feathers (Boonstra, 2013; Dantzer et al., 2014) or even fish scales. The effects of glucocorticoids on behaviour can also effectively be examined using glucocorticoid receptor blockers, such as RU486 in fish (Vijayan and Leatherland, 1992). Protocols could include combinations of these methods to describe not only levels of glucocorticoids in the blood, but also the sensitivity of tissues and downstream effects.

\subsection{Performance}

As ecological and evolutionary physiologists continue to explore the proximate causes and broad-scale significance of individual personalities and stress-coping styles, performance is an aspect of physiology that will be useful in bridging this gap. Performance metrics are useful in this way because selection is more likely to act on performance than more fundamental traits, such as metabolic rates or morphology (Careau and Garland, 2012). There has been recent interest in the relationship between metabolic rates, performance, and personality in an attempt to incorporate behaviour in pace-of-life syndromes, but other processes, such as endocrine systems, should also be explored because they are likely to affect performance and ultimately fitness (Ricklefs and Wikelski, 2002). For example, there is evidence that exogenous testosterone manipulations in male mountain spiny lizards (Sceloporus jarrovi) are related to levels of aggression and survival (Moore and Marler, 1987; Marler and Moore, 1989). Careau and Garland (2012) propose that tests that allow animals to choose their level of performance 
could reveal how motivation acts as a filter between an animal's maximum performance capacity and its actual performance, which might be related to personality. For example, some lizards appear to not exert their maximum running capacity, even when confronted with predator cues (Irschick and Garland, 2001; Braña, 2003; Irschick, 2003).

\subsection{The effects of context on behaviour and stress physiology}

One of the key challenges of studying both behaviour and physiological responses to stress is their sensitivity to external and internal factors; however, this is an interesting field of study in itself. External factors, such as resource availability, weather, anthropogenic disturbances, predators, and competition, as well as internal states, such as ontogeny, sex, and reproductive condition, are likely to affect behaviour and physiological responses to stress (Killen et al., 2013; Dantzer et al., 2014). Stability or fluctuations in environmental conditions also have the potential to affect these characteristics. Killen et al. (2013) propose a variety of ways in which challenging external environments could alter behaviour that warrant further study. For example, environmental conditions could alter the degree to which different physiological mechanisms control behaviour, or the direction of these relationships. Changes in external conditions could also augment or decrease individual differences in behaviour via physiological changes, such as stress responses, thus either increasing or decreasing the material on which selection could act. Intrinsic conditions, such as maturity, size, and fasting, also have the potential to affect behaviour (e.g., boldness; Bell and Stamps, 2004; Brown and Braithwaite, 2004; Thomson et al., 2012). For example, individuals that have been fasted are often observed to behave more boldly (Thomson et al., 2012). Similarly, Wendelaar Bonga (1997) highlights a number of factors that can modify physiological 
stress responses in teleost fish, including mineral and ionic composition of water, additional stressors, social interactions and crowding, life-stage, and both population and individual characteristics that are either acquired or inherited. Killen et al. (2013) suggest that studies on the effects of the environment on physiology and behaviour could potentially reveal the causal links between the two. However, Killen et al. (2013) recommend that researchers test these links within the context of challenging environments, whereas I propose that external conditions have the potential to alter behaviour, personality, and coping styles, whether or not they are perceived as challenging.

\subsection{Behavioural reaction norms}

I recommend that future studies of the relationships between individual behaviour and context also include measures of individual plasticity. Individuals vary not only in their average behaviour but also their plasticity along internal and external gradients (Dingemanse and Wolf, 2013). Behavioural reaction norms (BNRs) incorporate both the average behaviour of an individual and how this trait changes over a gradient (Dingemanse et al., 2009). These norms also describe the form of the relationship between a trait and environmental factors (Dingemanse et al., 2009). Stress-coping styles are a classic example of relationships between individual personality, plasticity, and physiological characteristics. For example, proactive, captive-bred rats and mice are less flexible in response to environmental challenges than reactive individuals, and these stress-coping styles are related to differences in physiological and neuroendocrine characteristics (Koolhaas et al., 1999). Although this relationship between stress-coping behaviour and plasticity is consistent in captive-bred rats and mice, there is evidence that 
these relationships can be more complex in natural populations of other species in the field (Ferrari et al., 2013). This emphasizes the need to test associations between personality, plasticity, and physiological characteristics in ecologically relevant contexts. Studies of this sort are rare (Dingemanse et al, 2009), but there are indications that individual differences in plasticity do occur in wild populations. For example, the frequency with which of female great tits provision their offspring is based on the interaction between chick begging intensity and genetic factors (Kölliker et al., 2000).

Dingemanse et al. (2009) discuss how evidence of consistent individual BNRs presents new imperatives and opportunities in personality research. For example, there has been a shift towards studying personality within natural environments so that results are demonstrated as ecologically relevant (Réale et al., 2007; Dingemanse and Réale, 2005). However, plastic individuals that are dispersed in a heterogeneous habitat might adapt their behaviour to their environment, making it difficult to compare behaviours among individuals assayed in the wild unless conditions are standardized or environmental conditions are accounted for. Although this approach requires more effort on the part of researchers because they must sample ecologically relevant information while testing individual behaviour in the field, this would also provide the opportunity for researchers to study how selection on different personalities varies in space and time, as well as how animals distribute themselves within an environment based on their individual characteristics (Dingemanse et al., 2009). Information of this sort could be used to develop models that describe how environmental conditions and fluctuation can affect the BNRs of individuals in wild populations or their distribution among habitats (Dingemanse et al., 2009). One way to test how personalities and plasticity develop based 
on context would be to raise genetically similar fish under a range of different conditions to see how these conditions influence the development of personalities, plasticity, and physiological characteristics.

\subsection{Fitness effects}

In addition to exploring the physiological mechanisms behind BNRs and stress-coping styles and how these are related to environmental conditions, evolutionary biologists and ecologists should seek to understand how these traits are related to the fitness of wild animals in their natural habitats. In the past, many have sought to demonstrate how aspects of animal physiology are related to fitness, but this has proven difficult for some characteristics. For example, despite widespread assumptions about how acute and chronic glucocorticoid stress responses affect condition and survival (Korte et al., 2005; Romero, 2004), researchers have struggled to demonstrate consistent relationships in wild populations (Bonier et al., 2009; Boonstra, 2013). As described above, personality and performance might be filters through which physiological characteristics impact fitness, and as such this is a promising field of research. There are a variety of theories as to how personalities and coping styles emerge and persist via natural selection (Biro and Stamps, 2008; Dall et al., 2004; McNamara et al., 2009; Royle et al., 2010; Schuett et al., 2011; Sih et al., 2004; Wolf and Weissing, 2010; Wolf et al., 2007, 2008, 2011) but at the present there is a great need to support these theories with evidence from wild populations within the context of BNRs.

There is evidence that animals with different BNRs are not distributed evenly across heterogeneous environments (Conover and Schultz, 1995), and studies of the non-random 
associations between environments and individual traits have the potential to yield insights into the evolutionary implications of BNRs, stress-coping styles, and behavioural syndromes. It could be that there is natural selection within certain environments for certain behavioural characteristics. For example, Dingemanse et al. (2007) found that for 12 populations of sticklebacks subject to different degrees of predation, correlations between certain behaviours were only present in populations from ponds with predators. It would be interesting to conduct common garden experiments with populations of the same species from isolated locations with different environmental regimes, such as environmental stability, human disturbance, or availability of hiding places, to see whether there are different BNRs in these populations. Physiological measures such as metabolic rates, baseline and stress induced glucocorticoids, and various performance capacities could also be compared among populations in such an experiment. These tests could be repeated on the offspring of these populations raised in identical laboratory environments to determine whether the origins of differences in BNRs have a genetic basis.

\subsection{From individual differences to conservation strategies}

An understanding the physiological responses of individual wild animals to environmental conditions, and their implications for individual fitness, could provide conservation biologists with tools to assess, predict, and mitigate the effects of environmental disturbance on populations (Wikelski and Cooke, 2006; Cooke et al., 2013). For example, if we are able to characterize the baseline and stress induced physiological and behavioural characteristics of a population, these could serve as indicators of stress in a population and can be used to predict deleterious effects (Dantzer 
et al., 2014). For example, disturbance of endangered yellow-eyed penguins (Megadyptes antipodes) by tourists was linked to high baseline levels of corticosterone relative to a population of undisturbed penguins, which might be related to observed reductions in condition (Ellenberg et al., 2007) . If researchers were able to establish relationships between levels of disturbance and detrimental effects on fitness and population health, they could define an acceptable level of disturbance as indicated by physiological characteristics (such as glucocorticoid levels) and include this in monitoring and management strategies.

If we understand how certain contexts exert selection on BNRs in populations, then we can take measures to mitigate potential deleterious effects. For example, hatchery fish tend to be faster growing, bolder, and more aggressive than wild strains (Huntingford, 2004; Huntingford and Adams, 2005; Salonen and Peuhkuri, 2006; Sundström et al., 2004), characteristics that can reduce their competitive ability and survival once they are released in the wild, depending on the context (Huntingford and Garcia de Leaniz, 1997; Metcalfe et al., 2003). Conrad et al. (2011) provide recommendations for increasing the diversity of potentially adaptive personalities in hatchery fish in order to improve the success of stocking programs. Assessments of behavioural plasticity in response to environmental change could be particularly useful in identifying which species or personality types are likely to adjust successfully to environmental change and disturbance. 


\subsection{Summary}

Despite a growing recognition of the implications of personality, plasticity, and stresscoping styles for evolutionary and ecological processes, there have been difficulties in incorporating these factors into potential conservation strategies. This might be a result of the current challenges in characterizing their individual fitness and population level effects in wild animals. Ongoing improvements to the methodologies used to study stress, as well as a trend towards performing more ecologically relevant tests of personality and plasticity, will contribute towards a greater understanding of the links between these characteristics, how they are related to individual fitness in current and changing environments, and how this can scale up to population-level effects. These developments should promote the incorporation of these concepts into conservation strategies and will potentially contribute towards more effective mitigation of the effects of disturbance and environmental change. 


\section{References}

Archard, G.A., V.A. Braithwaite, The importance of wild populations in studies of animal temperament, J. Zool. 281 (2010) 149-160.

Barton, B.A., Stress in fishes: a diversity of responses with particular reference to changes in circulating corticosteroids, Integr. Comp. Biol. 42 (2002) 517-525.

Barton, B.A., C.B. Schreck, L.D. Barton, Effects of chronic cortisol administration and daily acute stress on growth, physiological conditions, and stress responses in juvenile rainbow trout, Dis. Aquat. Organ. 2 (1987) 173-185.

Bell, A.M., Future directions in behavioural syndromes research, Proc. Roy. Soc. B: Biol. 274 (2007) 755-761.

Bell, A.M., Behavioural differences between individuals and two populations of stickleback (Gasterosteus aculeatus), J. Evol. Biol. 18 (2005) 464-473.

Bell, A.M., J.A. Stamps, Development of behavioural differences between individuals and populations of sticklebacks, Gasterosteus aculeatus, Anim. Behav. 68 (2004) 1339-1348.

Bell, A.M., T. Backström, F.A. Huntingford, T.G. Pottinger, S. Winberg, Variable neuroendocrine responses to ecologically-relevant challenges in sticklebacks, Physiol. Behav. 91 (2007) 15-25.

Bell, A.M., S.J. Hankison, K.L. Laskowski, The repeatability of behaviour: a metaanalysis, Anim. Behav. 77 (2009) 771-783.

Biro, P.A., J.A. Stamps, Are animal personality traits linked to life-history productivity? Trends Ecol. Evol. 23 (2008) 361-368.

Biro, P.A., J.A. Stamps, Do consistent individual differences in metabolic rate promote consistent individual differences in behavior? Trends Ecol. Evol. 25 (2010) 653659.

Bonier, F., P.R. Martin, I.T. Moore, J.C. Wingfield, Do baseline glucocorticoids predict fitness? Trends Ecol. Evol. 24 (2009) 634-642.

Boonstra, R., Reality as the leading cause of stress: rethinking the impact of chronic stress in nature, Funct. Ecol. 27 (2013) 11-23.

Boonstra, R., D. Hik, G.R. Singleton, A. Tinnikov, The impact of predator-induced stress on the snowshoe hare cycle, Ecol. Monogr. 79 (1998) 317-394.

Brainerd, E.L., Pufferfish inflation: functional morphology of postcranial structures in Diodon holocanthus (Tetraodontiformes), J. Morphol. 220 (1994) 243-261. 
Braña F., Morphological correlates of burst speed and field movement patterns: the behavioural adjustment of locomotion in wall lizards (Podarcis muralis), Biol. J. Linn. Soc. 80 (2003) 135-146.

Brown, C., V.A. Braithwaite, Size matters: a test of boldness in eight populations of the poeciliid Brachyraphis episcopi, Anim. Behav. 68 (2004) 1325-1329.

Budaev, S.V., D.D. Zworykin, A.D. Mochek, Consistency of individual differences in behaviour of the lion-headed cichlid, Steatocranus casuarius, Behav. Process. 48 (1999) 49-55.

Careau, V., T. Garland Jr., Performance, personality, and energetics: correlation, causation, and mechanism, Physiol. Biochem. Zool. 85 (2012) 543-571.

Cochran, W.G., Some methods for strengthening the common $\chi^{2}$ tests, Biometrics 10 (1954) 417-451.

Conover, D.O., E.T. Schultz, Phenotypic similarity and the evolutionary significance of countergradient variation, Trends Ecol. Evol. 10 (1995) 248-252.

Conrad, J.L., K.L. Weinersmith, T. Brodin, J.B. Saltz, A. Sih, Behavioural syndromes in fishes: a review with implications for ecology and fisheries management, J. Fish Biol. 78 (2011) 395-435.

Contente, R.F., M.F. Stefanoni, H.L. Spach, Fish assemblage structure in an estuary of the Atlantic Forest biodiversity hotspot (southern Brazil), Ichthyol. Res. 58 (2011) $38-50$.

Cooke, S.J., L. Sack, C.E. Franklin, A.P. Farrell, J. Beardall, M. Wikelski, S.L. Chown, What is conservation physiology? Perspectives on an increasingly integrated and essential science, Conserv. Phys. 1 (2013) 1-23.

Cote, J., S. Fogarty, K. Weinersmith, T. Brodin, A. Sih, Personality traits and dispersal tendency in the invasive mosquitofish (Gambusia affinis), Proc. Roy. Soc. B: Biol. 277 (2010) 1571-1579.

Chambers, J.M., Linear models, In J.M. Chambers and T.J. Hastie (Eds.), Statistical Models in S, Wadsworth \& Brooks/Cole, Pacific Grove, 1992.

Creel, S., J.A. Winnie Jr., D. Christianson, Glucocorticoid stress hormones and the effect of predation risk on elk reproduction, Proc. Nat. Acad. Sci. USA 106 (2009) $12388-12393$.

Cull, F., C.M. O’Connor, C.D. Suski, A. Shultz, A.J. Danylchuk, S.J. Cooke, Puff and bite: The relationship between the glucocorticoid stress response and anti-predator performance in checkered puffer (Sphoeroides testudineus), Gen. Comp. Endocr. 214 (2015a) 1-8. 
Cull, F., C.D. Suski, A. Shultz, A.J. Danylchuk, C.M. O’Connor, K.J. Murchie, S.J. Cooke, Consequences of experimental cortisol manipulations on the thermal biology of the checkered puffer (Sphoeroides testudineus) in laboratory and field environments, J. Therm. Biol. 47 (2015b) 63-74.

Dall, S.R., A.I. Houston, J.M. McNamara, The behavioural ecology of personality: consistent individual differences from an adaptive perspective, Ecol. Lett. 7 (2004) 734-739.

Dantzer, B., Q.E., Fletcher, R. Boonstra, M.J. Sheriff, Measures of physiological stress: a transparent or opaque window into the status, management and conservation of species? Cons. Phys. 2 (2014) 1-18.

Davis, W., Passage of Darkness: The Ethnobiology of the Haitian Zombie, The University of North Carolina Press, 1988, 107-165.

Deeds, J.R., K.D. White, S.M. Etheridge, J.H. Landsberg, Concentrations of saxitoxin and tetrodotoxin in three species of puffers from the Indian River Lagoon, Florida, the location for multiple cases of saxitoxin puffer poisoning from 2002 to 2004, T. Am. Fish. Soc. 137 (2008) 1317-1326.

de Jong, G., S. Gavrilets, Maintenance of genetic variation in phenotypic plasticity: the role of environmental variation, Genet. Res. 76 (2000) 295-304.

DeWitt, T.J., A. Sih, D.S. Wilson, Costs and limits of phenotypic plasticity, Trends Ecol. Evol. 13 (1998) 77-81.

Dey, C.J., C.M. O'Connor, K.M. Gilmour, G. Van Der Kraak, S.J. Cooke, Behavioral and physiological responses of a wild teleost fish to cortisol and androgen manipulations during parental care, Horm. Behav. 58 (2010) 599-605.

DiBattista, J.D., H. Anisman, M. Whitehead, K.M. Gilmour, The effects of cortisol administration on social status and brain monoaminergic activity in rainbow trout Oncorhynchus mykiss, J. Exp. Biol. 208 (2005) 2707-2718.

Dingemanse, N.J., D. Réale, Natural selection and animal personality, Behaviour 142 (2005) 1165-1190.

Dingemanse, N.J., M. Wolf, Between-individual differences in behavioural plasticity within populations: causes and consequences, Anim. Behav. 85 (2013) 10311039 .

Dingemanse, N.J., C. Both, A.J. van Noordwijk, A.L. Rutten, P.J. Drent, Natal dispersal and personalities in great tits (Parus major), Proc. Roy. Soc. B 270 (2003) 741747. 
Dingemanse, N.J., C. Both, P.J. Drent, J.M. Tinbergen, Fitness consequences of avian personalities in a fluctuating environment, Proc. Roy. Soc. B: Biol. 271 (2004) 847-852.

Dingemanse, N.J., J. Wright, A.J. Kazem, D.K. Thomas, R. Hickling, N. Dawnay, Behavioural syndromes differ predictably between 12 populations of three-spined stickleback, J. Anim. Ecol. 76 (2007) 1128-1138.

Dingemanse, N.J., F. Van der Plas, J. Wright, D. Réale, M. Schrama, D.A. Roff, E. Van der Zee, I. Barber, Individual experience and evolutionary history of predation affect expression of heritable variation in fish personality and morphology, Proc. Roy. Soc. B: Biol. (2009) rspb-2008.

Duckworth, R.A., Evolution of personality: developmental constraints on behavioral flexibility, The Auk, 127 (2010) 752-758.

Ellenberg U., A.N. Setiawan, A. Cree, D.M. Houston, P.J. Seddon, Elevated hormonal stress response and reduced reproductive output in yellow-eyed penguins exposed to unregulated tourism, Gen. Comp. Endocr. 152 (2007) 54-63.

Ellison, A.M., E.J. Farnsworth, Anthropogenic disturbance of Caribbean mangrove ecosystems: past impacts, present trends, and future predictions, Biotropica (1996) 549-565.

Falconer, D.S., T.F.C. Mackay, Introduction to Quantitative Genetics, 4th edn, Longman Group Ltd, New York, 1996, 134-135.

Farwell, M., M.L. Fuzzen, N.J. Bernier, R.L. McLaughlin, Individual differences in foraging behavior and cortisol levels in recently emerged brook charr (Salvelinus fontinalis), Behav. Ecol. Sociobiol. 68 (2014) 781-790.

Ferrari, C., C. Pasquaretta, C. Carere, E. Cavallone, A. von Hardenberg, D. Réale, Testing for the presence of coping styles in a wild mammal, Anim. Behav. 85 (2013) 1385-1396.

Field, A., J. Miles, Z. Field, Discovering Statistics Using R, SAGE Publications Ltd, London, 2012.

Fraser, D.F., J.F. Gilliam, M.J. Daley, A.N. Le, G.T. Skalski, Explaining leptokurtic movement distributions: intrapopulation variation in boldness and exploration, Am. Nat. 158 (2001) 124-135.

Gamperl, A.K., M.M. Vijayan, R.G. Boutilier, Experimental control of stress hormone levels in fishes: techniques and applications, Rev. Fish Biol. Fish. 4 (1994) 215255.

Gosling, S.D., From mice to men: what can we learn about personality from animal research? Psychol. Bull. 127 (2001) 45-86. 
Goymann, W., On the use of non-invasive hormone research in uncontrolled, natural environments: the problem with sex, diet, metabolic rate and the individual, Method. Ecol. Evol. 3 (2012) 757-765.

Gregory, T.R., C.M. Wood, The effects of chronic plasma cortisol elevation on the feeding behaviour, growth, competitive ability, and swimming performance of juvenile rainbow trout, Physiol. Biochem. Zool. 72 (1999) 286-295.

Hanson, K.C., S.J. Cooke, S.G. Hinch, G.T. Crossin, D.A. Patterson, K.K. English, M.R. Donaldson, J.M. Shrimpton, G. Van Der Kraak, A.P. Farrell, Individual variation in migration speed of upriver-migrating sockeye salmon in the Fraser River in relation to their physiological and energetic status at marine approach, Physiol. Biochem. Zool. 81 (2008) 255-268.

Hanson, K.C., C.T. Hasler, M.R. Donaldson, S.J. Cooke, Stability of swimming performance and activity hierarchies among wild largemouth bass at multiple temporal scales: evidence for context-dependent shuffling between seasons, Can. J. Zool. 88 (2010) 324-333.

Heath, A.G., J.J. Cech Jr., J.G. Zink1, M.D. Steele, Sublethal effects of three pesticides on Japanese medaka, Arch. Environ. Con. Tox. 25 (1993) 485-491.

Hosoya, S., T. Kaneko, Y. Suzuki, A. Hino, Individual variations in behavior and free cortisol responses to acute stress in tiger pufferfish Takifugu rubripes, Fish. Sci. 74 (2008) 755-763.

Houston, A.H., J.A. Madden, R.J. Woods, H.M. Miles, Some physiological effects of handling and tricaine methane-sulphonate anesthetization upon the brook trout, Salvelinus fontinalis, J. Fish. Res. Board Can. 28 (1971) 625-633.

Huntingford, F.A., Implications of domestication and rearing conditions for the behaviour of cultivated fishes, J. Fish Biol. 65 (2004) 122-142.

Huntingford, F., C. Adams, Behavioural syndromes in farmed fish: implications for production and welfare, Behaviour 142 (2005) 1207-1221.

Huntingford, F.A., C. Garcia de Leaniz, Social dominance, prior residence and the acquisition of profitable feeding sites in juvenile Atlantic salmon, J. Fish Biol. 51 (1997) 1009-1014.

Husak J.F., Does survival depend on how fast you can run or how fast you do run? Funct. Ecol. 20 (2006)1080-1086.

Husak J.F., S.F. Fox, Field use of maximal sprint speed by collared lizards (Crotaphytus collaris): compensation and sexual selection, Evolution 60 (2006) 1888-1895.

Irschick D.J., Measuring performance in nature: implications for studies of fitness within populations, Integr. Comp. Biol. 43 (2003) 396-407. 
Irschick, D.J., T. Garland Jr., Integrating function and ecology in studies of adaptation: investigations of locomotor capacity as a model system, Annu. Rev. Ecol. Syst. (2001) 367-396.

Irschick D.J., A.V. Herrel, B. Vanhooydonck, K. Huyghe, R. Van Damme, Locomotor compensation creates a mismatch between laboratory and field estimates of escape speed in lizards: a cautionary tale for performance-to-fitness studies, Evolution 59 (2005) 1579-1587.

Iwama, G.K., J.C. McGeer, M.P. Pawluk, The effects of five fish anaesthetics on acidbase balance, hematocrit, blood gases, cortisol, and adrenaline in rainbow trout, Can. J. Zool. 67 (1989) 2065-2073.

Ketterson, E.D., V.A.L. Nolan, M.J. Cawthorn, P.G. Parker, C. Ziegenfus, Phenotypic engineering: using hormones to explore the mechanistic and functional bases of phenotypic variation in nature, Ibis 138 (1996) 70-86.

Killen, S.S., S. Marras, D.J. McKenzie, Fuel, fasting, fear: routine metabolic rate and food deprivation exert synergistic effects on risk-taking in individual juvenile European sea bass, J. Anim. Ecol. 80 (2011) 1024-1033.

Killen, S.S., S. Marras, M.R. Ryan, P. Domenici, D.J. McKenzie, A relationship between metabolic rate and risk-taking behaviour is revealed during hypoxia in juvenile European sea bass, Funct. Ecol. 26 (2012) 134-143.

Killen, S.S., S. Marras, N.B. Metcalfe, D.J. McKenzie, P. Domenici, Environmental stressors alter relationships between physiology and behaviour, Trends Ecol. Evol. 28 (2013) 651-658.

Kölliker, M. Martin, W.G. Brinkhof, P. Heeb, P.S. Fitze, H. Richner, The quantitative genetic basis of offspring solicitation and parental response in a passerine bird with parental care, Proc. Roy. Soc. Lond. B 267 (2000) 2127-2132.

Koolhaas, J.M., S.M. Korte, S.F. De Boer, B.J. Van Der Vegt, C.G. Van Reenen, H. Hopster, I.C. De Jong, M.A.W. Ruis, H.J. Blokhuis, Coping styles in animals: current status in behavior and stress-physiology, Neurosci. Biobehav. Rev. 23 (1999) 925-935.

Koolhaas, J.M., S.F. de Boer, B. Buwalda, K. van Reenen, Individual variation in coping with stress: a multidimensional approach of ultimate and proximate mechanisms, Brain Behav. Evol. (2007) 218-226.

Koolhaas, J.M., S.F. De Boer, C.M. Coppens, B. Buwalda, Neuroendocrinology of coping styles: towards understanding the biology of individual variation, Front. Neuroendocrine. 31 (2010) 307-321. 
Korte, S.M., J.M. Koolhaas, J.C. Wingfield, B.S. McEwen, The Darwinian concept of stress: benefits of allostasis and costs of allostatic load and the trade-offs in health and disease, Neurosci. Biobehav. Rev. 29 (2005) 3-38.

Lankford, S.E., T.E. Adams, R.A. Miller, J.J. Cech Jr., The cost of chronic stress: impacts of a nonhabituating stress response on metabolic variables and swimming performance in sturgeon, Physiol. Biochem. Zool. 78 (2005) 599-609.

Malisch, J.L., C.W. Breuner, F.R. Gomes, M.A. Chappell, T. Garland Jr., Circadian pattern of total and free corticosterone concentrations, corticosteroid-binding globulin, and physical activity in mice selectively bred for high voluntary wheelrunning behavior, Gen. Comp. Endocr. 156 (2008) 210-217.

Mantel, N., W. Haenszel, Statistical aspects of the analysis of data from retrospective studies of disease, J. Natl. Cancer Inst. 22 (1959) 719-748.

Marler, C.A., M.C. Moore, Time and energy costs of aggression in testosteroneimplanted free-living male mountain spiny lizards (Sceloporus jarrovi), Physiol. Zool. 62 (1989) 1334-1350.

Mather, J.A., D.M. Logue, The bold and the spineless: invertebrate personalities, In C. Carere and D. Maestripieri (Eds.), Animal Personalities: Behaviour, Physiology, and Evolution, The University of Chicago Press, Chicago, 2013, 13-35.

McCormick, S.D., J.M. Shrimpton, J.B. Carey, M.F. O'dea, K.E., Sloan, S. Moriyama, B.T. Björnsson, Repeated acute stress reduces growth rate of Atlantic salmon parr and alters plasma levels of growth hormone, insulin-like growth factor I and cortisol, Aquaculture 168 (1998) 221-235.

McDougall, P.T., D. Réale, D. Sol, S.M. Reader, Wildlife conservation and animal temperament: causes and consequences of evolutionary change for captive, reintroduced, and wild populations, Anim. Conserv. 9 (2006) 39-48.

McGee, G.E., T.D. Clark, All puffed out: do pufferfish hold their breath while inflated? Biol. Letters 10 (2014) 20140823.

McNamara, J.M., P.A. Stephens, S.R. Dall, A.I. Houston, Evolution of trust and trustworthiness: social awareness favours personality differences, Proc. Roy. Soc. Lond. B 276 (2009) 605-613.

Metcalfe, N.B., S.K. Valdimarsson, I.J. Morgan, The relative roles of domestication, rearing environment, prior residence and body size in deciding territorial contests between hatchery and wild juvenile salmon, J. Appl. Ecol. 40 (2003) 535-544.

Mommsen, T.P., M.M. Vijayan, T.W. Moon, Cortisol in teleosts: dynamics, mechanisms of action, and metabolic regulation, Rev. Fish Biol. Fish. 9 (1999) 211-268. 
Moore, M.C., C.A. Marler, Effects of testosterone manipulations on nonbreeding season territorial aggression in free-living male lizards, Sceloporus jarrovi, Gen. Comp. Endocr. 65 (1987) 225-232.

Nussey, D.H., A.J. Wilson, J.E. Brommer, The evolutionary ecology of individual phenotypic plasticity in wild populations, J. Evol. Biol. 20 (2007) 831-844.

O'Connor, C.M., K.M. Gilmour, R. Arlinghaus, G. Van Der Kraak, S.J. Cooke, Stress and parental care in a wild teleost fish: insights from exogenous supraphysiological cortisol implants, Physiol. Biochem. Zool. 82 (2009) 709-711.

O'Connor, C.M., K.M. Gilmour, R. Arlinghaus, C.T. Hasler, D.P. Philipp, S. J. Cooke, Seasonal carryover effects following the administration of cortisol to a wild teleost, Physiol. Biochem. Zool. 83 (2010) 950-957.

O'Connor, C.M., K.M. Gilmour, R. Arlinghaus, S. Matsumura, C.D. Suski, D.P. Philipp, S.J. Cooke, The consequences of short-term cortisol elevation of individual physiology and growth rate in wild largemouth bass (Micropterus salmoides), Can. J. Fish. Aquat. Sci. 68 (2011) 1-13.

Øverli, Ø., S. Kotzian, S. Winberg, Effects of cortisol on aggression and locomotor activity in rainbow trout, Horm. Behav. 42 (2002a) 53-61.

Øverli, Ø., T.G. Pottinger, T.R. Carrick, E. Øverli, S. Winberg, Differences in behaviour between rainbow trout selected for high-and low-stress responsiveness, J. Exp. Biol. 205 (2002b) 391-395.

Øverli, Ø., S. Winberg, T.G. Pottinger, Behavioral and neuroendocrine correlates of selection for stress responsiveness in rainbow trout—a review, Integr. Comp. Biol. 45 (2005) 463-474.

Øverli, Ø., C. Sørensen, K.G. Pulman, T.G. Pottinger, W. Korzan, C.H. Summers, G.E. Nilsson, Evolutionary background for stress-coping styles: relationships between physiological, behavioral, and cognitive traits in non-mammalian vertebrates, Neurosci. Biobehav. Rev. 31 (2007) 396-412.

Pankhurst, N.W., The endocrinology of stress in fish: an environmental perspective, Gen. Comp. Endocr. 170 (2011) 265-275.

Peto, R., J. Peto, Asymptotically efficient rank invariant test procedures, J. Roy. Stat. Soc. Series A (1972) 185-207.

Portz, D.E., C.M., Woodley, J.J. Cech Jr., Stress-associated impacts of short-term holding on fishes, Rev. Fish Biol. Fish. 16 (2006) 125-170.

Portz, D.E., Fish-Holding-Associated Stress in Sacramento River Chinook Salmon (Oncorhynchus tshawytscha) at South Delta Fish Salvage Operations: Effects on 
Plasma Constituents, Swimming Performance, and Predator Avoidance, PhD dissertation, University of California, Davis, 2007.

R Core Team, R: a language and environment for statistical computing (Version 3.0.3) [Software], Vienna, 2014, http://www.R-project.org/

Randall J.E., Food habits of reef fishes of the West Indies, Stud. Trop. Oceanogr. 5 (1967) 665-847.Réale, D., S.M. Reader, D. Sol, P.T. McDougall, N.J. Dingemanse, Integrating animal temperament within ecology and evolution, Biol. Rev. 82 (2007) 291-318.

Réale, D., D. Garant, M.M. Humphries, P. Bergeron, V. Careau, P.O. Montiglio, Personality and the emergence of the pace-of-life syndrome concept at the population level, Philos. T. Roy. Soc. B: Biol. 365 (2010) 4051-4063.

Recher, H.F., J.A. Recher, Comments on the escape of prey from avian predators, Ecology 49 (1968) 560-562.

Ricklefs R.E., M. Wikelski, The physiology/life-history nexus, Trends Ecol. Evol. 17 (2002) 462-468.

Romero, L.M., Physiological stress in ecology: lessons from biomedical research, Trends Ecol. Evol. 19 (2004) 249-255.

Royle, N.J., W. Schuett, S.R. Dall, Behavioral consistency and the resolution of sexual conflict over parental investment, Behav. Ecol. (2010) arq156.

Salonen, A., N. Peuhkuri, The effect of captive breeding on aggressive behaviour of European grayling, Thymallus thymallus, in different contexts, Anim. Behav. 72 (2006) 819-825.

Sapolsky, R.M., Individual differences in cortisol secretory patterns in the wild baboon: role of negative feedback sensitivity, Endocrinology 113 (1983) 2263-2267.

Sapolsky, R.M., L.M. Romero, A.U. Munck, How do glucocorticoids influence stress responses? Integrating permissive, suppressive, stimulatory, and preparative actions, Endocr. Rev. 21 (2000) 55-89.

Schjolden, J., K.G.T. Pulman, T.G. Pottinger, N.B. Metcalfe, S. Winberg, Divergence in locomotor activity between two strains of rainbow trout Oncorhynchus mykiss with contrasting stress responsiveness, J. Fish Biol. 68 (2006) 920-924.

Schreck, C.B., B.L. Olla, M.W. Davis, Behavioral responses to stress, In G.K. Iwama, A.D. Pickering, J.P. Sumpter, C.B. Schreck (Eds.), Fish Stress and Health in Aquaculture, Cambridge University Press, Cambridge, 1997, 145-170.

Schuett, W., S.R. Dall, N.J. Royle, Pairs of zebra finches with similar 'personalities' make better parents, Anim. Behav. 81 (2011) 609-618. 
Schürch, R., D. Heg, Life history and behavioral type in the highly social cichlid Neolamprologus pulcher, Behav. Ecol. 21 (2010a) 588-598.

Schürch, R., D. Heg, Variation in helper type affects group stability and reproductive decisions in a cooperative breeder, Ethology 116 (2010) 257-269.

Sheriff, M.J., C.J. Krebs, R. Boonstra, From process to pattern: how fluctuating predation risk impacts the stress axis of snowshoe hares during the 10-year cycle, Oecologia 166 (2011) 593-605.

Shipp, R.L., The pufferfishes (Tetraodontidae) of the Atlantic Ocean, Publ. Gulf Coast Res. Lab. Museum 4 (1974) 163.

Shultz, A.D., Z.C. Zuckerman, H.A. Stewart, C.D. Suski, Seasonal blood chemistry response of sub-tropical nearshore fishes to climate change, Cons. Phys. 2 (2014) $1-12$.

Sih, A., Prey uncertainty and the balancing of antipredator and feeding needs, Am. Nat. 139 (1992) 1052-1069.

Sih, A., A.M. Bell, Insights for behavioral ecology from behavioral syndromes, Adv. Stud. Behav. 38 (2008) 227-281.

Sih, A., L.B. Kats, E.F. Maurer, Behavioural correlations across situations and the evolution of antipredator behaviour in a sunfish-salamander system, Anim. Behav. 65 (2003) 29-44.

Sih, A., A.M. Bell, J.C. Johnson, Behavioral syndromes: an ecological and evolutionary overview, Trends Ecol. Evol. 19 (2004) 372-378.

Silva, P.I.M., C.I. Martins, S. Engrola, G. Marino, Ø. Øverli, L.E. Conceição, Individual differences in cortisol levels and behaviour of Senegalese sole (Solea senegalensis) juveniles: evidence for coping styles, Appl. Anim. Behav. Sci. 124 (2010) 75-81.

Smith, B.R., D.T. Blumstein, Fitness consequences of personality: a metaanalysis, Behav. Ecol. 19 (2008) 448-455.

Sundström, L.F., E. Petersson, J. Höjesjö, J.I. Johnsson, T. Järvi, Hatchery selection promotes boldness in newly hatched brown trout (Salmo trutta): implications for dominance, Behav. Ecol. 15 (2004) 192-198.

Systat Software, Inc., SigmaPlot for Windows (Version 11.0, build 11.0.0.77) [Software], (2008).

Targett, T.E., Food resource partitioning by the pufferfishes Sphoeroides spengeleri and S. testudineus from Biscayne Bay, Florida, Mar. Biol. 49 (1979) 83-91. 
Taylor, M.K., S.J. Cooke, Repeatability of movement behaviour in a wild salmonid revealed by telemetry, J. Fish Biol. 84 (2014) 1240-1246.

Thiem, J.D., C. Hatry, J.W. Brownscombe, F. Cull, A.D. Shultz, A.J. Danylchuk, S.J. Cooke, Evaluation of radio telemetry to study the spatial ecology of checkered puffers (Sphoeroides testudineus) in shallow tropical marine systems, Bull. Mar. Sci. 89 (2013) 559-569.

Thomson, J.S., P.C. Watts, T.G. Pottinger, L.U. Sneddon, Plasticity of boldness in rainbow trout, Oncorhynchus mykiss: do hunger and predation influence risktaking behaviour? Horm. Behav. 61 (2012) 750-757.

Vega-Cendejas, M.E., M.H. de Santillana, Fish community structure and dynamics in a coastal hypersaline lagoon: Rio Lagartos, Yucatan, Mexico, Estuar. Coast. Shelf Sci. 60 (2004) 285-299.

Vijayan, M.M., J.F. Leatherland, In vivo effects of the steroid analogue RU486 on some aspects of intermediary and thyroid metabolism of brook charr, Salvelinus fontinalis, J. Exp. Zool. 263 (1992) 265-271.

Wendelaar Bonga, S., The stress response in fish, Physiol. Rev. 77 (1997) 591-625.

Wikelski, M., S.J. Cooke, Conservation physiology, Trends Ecol. Evol. 21 (2006) 38-46.

Wikelski, M., L. Spinney, W. Schelsky, A. Scheuerlein, E. Gwinner, Slow pace of life in tropical sedentary birds: a common-garden experiment on four stonechat populations from different latitudes, Proc. R. Soc. Lond. B 270 (2003) 23832388 .

Williams, T.D., Individual variation in endocrine systems: moving beyond the tyranny of the golden mean, Philos. T. Roy. Soc. B 363 (2008) 1687-1698.

Wilson, A.D., R.L. McLaughlin, Behavioural syndromes in brook charr, Salvelinus fontinalis: prey-search in the field corresponds with space use in novel laboratory situations, Anim. Behav. 74 (2007) 689-698.

Wilson, A.D.M., T.R. Binder, K.P. McGrath, S.J. Cooke, J.-G. J. Godin, Capture technique and fish personality: angling targets timid bluegill sunfish, Lepomis macrochirus, Can. J. Fish. Aquat. Sci. 68 (2011) 749-757.

Wolf, M., F.J. Weissing, An explanatory framework for adaptive personality differences, Philos. T. Roy. Soc. B: Biol. 365 (2010) 3959-3968.

Wolf, M., G.S. Van Doorn, O. Leimar, F.J. Weissing, Life-history trade-offs favour the evolution of animal personalities, Nature 447 (2007) 581-584.

Wolf, M., G.S. Van Doorn, F.J. Weissing, Evolutionary emergence of responsive and unresponsive personalities, Proc. Natl. Acad. Sci. 105 (2008) 15825-15830. 
Wolf, M., G.S. Van Doorn, F.J. Weissing, On the coevolution of social responsiveness and behavioural consistency, Proc. Roy. Soc. B: Biol. 278 (2011) 440-448.

Woodworth, L.M., M.E. Montgomery, D.A. Briscoe, R. Frankham, Rapid genetic deterioration in captive populations: causes and conservation implicatio

\section{Appendix- Statements of permission from co-authors}

\section{9:12 AM March 27, 2015}

From: Naomi Pleizier

\section{To: Aaron Shultz and Alex Wilson}

Hi Alex and Aaron,

As you know, I'm using the paper that we have co-authored as part of my thesis. I'm required to include statements of permission from all my co-authors; I've attached my description of your roles in the project. Would you mind sending me your statements of permission?

Thanks for the help!

Naomi

10:18 AM March 27, 2015

From: Aaron Shultz

To: Naomi Pleizier

You have my permission.

\section{1:51 AM March 30, 2015}

From: Alex Wilson

To: Naomi Pleizier

Naomi Pleizier has my support and permission as a co-author, to use the manuscript(s) that we have collaborated on for her MSc thesis in Biology at Carleton University. 